\title{
Melengestrol acetate (MGA) as an effective alternative to induce molting in laying hens
}

\author{
Jill Marie Koch \\ West Virginia University
}

Follow this and additional works at: https://researchrepository.wvu.edu/etd

\section{Recommended Citation}

Koch, Jill Marie, "Melengestrol acetate (MGA) as an effective alternative to induce molting in laying hens" (2005). Graduate Theses, Dissertations, and Problem Reports. 2183.

https://researchrepository.wvu.edu/etd/2183

This Thesis is protected by copyright and/or related rights. It has been brought to you by the The Research Repository @ WVU with permission from the rights-holder(s). You are free to use this Thesis in any way that is permitted by the copyright and related rights legislation that applies to your use. For other uses you must obtain permission from the rights-holder(s) directly, unless additional rights are indicated by a Creative Commons license in the record and/ or on the work itself. This Thesis has been accepted for inclusion in WVU Graduate Theses, Dissertations, and Problem Reports collection by an authorized administrator of The Research Repository @ WVU. For more information, please contact researchrepository@mail.wvu.edu. 
Melengestrol acetate (MGA) as an effective alternative to induce molting in laying hens

by

Jill Marie Koch

Thesis submitted to the Davis College of Agriculture Forestry and Consumer Sciences at West Virginia University in partial fulfillment of the requirements for the degree of

\author{
Master of Science \\ in \\ Reproductive Physiology
}

Approved by

Matthew E. Wilson, Committee Chairperson

Donald C. Lay Jr.

Joseph S. Mortiz

Division: Animal and Veterinary Science

Morgantown, WV

2005

Keywords: Chicken, Molting, Melengestrol Acetate, Well-being 


\begin{abstract}
Melengestrol acetate (MGA) as an effective alternative to induce molting in laying hens
\end{abstract}

\author{
Jill Marie Koch
}

The current experiments were conducted to determine if an orally active progestin, melengestrol acetate (MGA), would be an effective method to induce molting that addresses hen well-being during and after molt. MGA can easily be administered to a large population because it is orally active and can be included in a balanced layer diet. Hens could be fed throughout the molting process, which would address the concerns brought about by other methods in that there is a nutrient deficiency that results in hen weight loss. If feeding MGA can effectively lead to a reversible regression of the oviduct then it may also lead to an increase in egg quality post-molt. 


\section{Table of Contents}

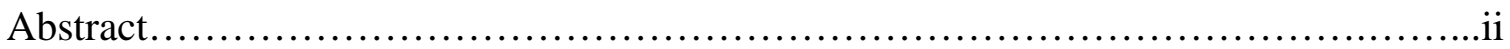

Table of Contents..........................................................................

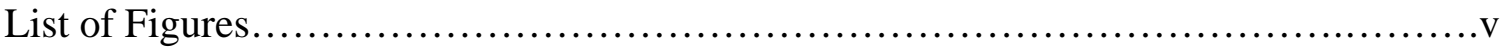

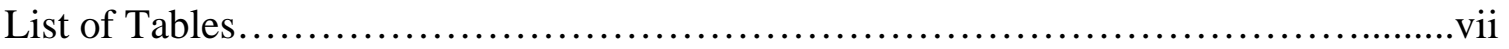

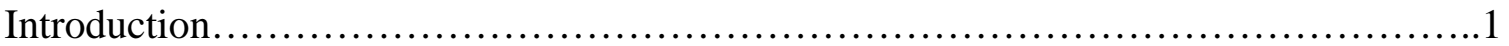

Review of Literature.......................................................... 4

General Structures and Secretions...........................................

Sex Steroid Production............................................. 4

Theca Cells and Estrogen............................................. 5

Granulosa Cell and Progesterone........................................6

Egg Components....................................................... 8

Lay Cycle...............................................................

Molting.................................................................. 10

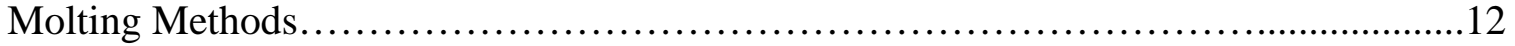

Nutrient Manipulation..................................................13

Hormone Induced Molt...........................................15

Assessing Hunger..........................................................

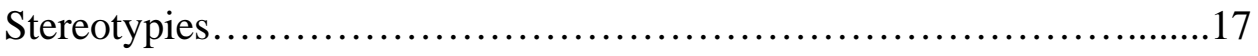

Hen Well-being.......................................................

Motivation Testing.......................................................

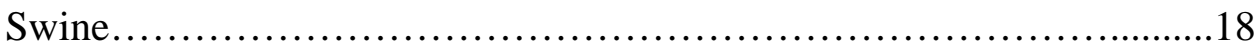

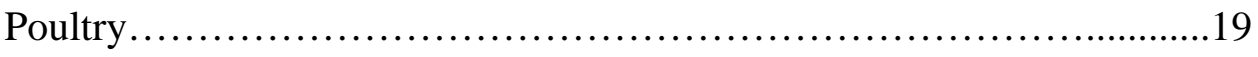

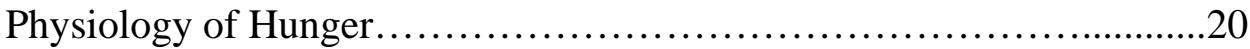

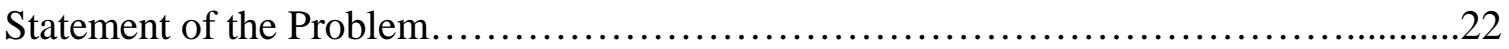

Melengestrol acetate as an alternative method to induce molting .........................25

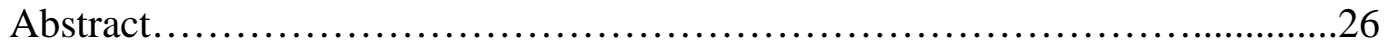

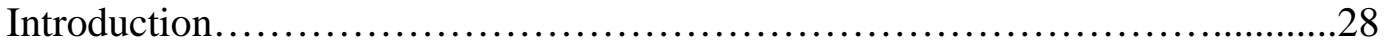

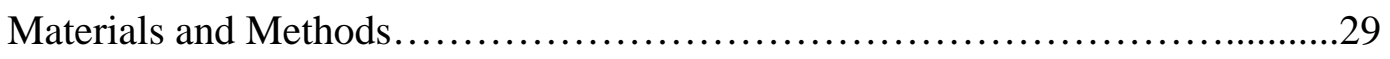

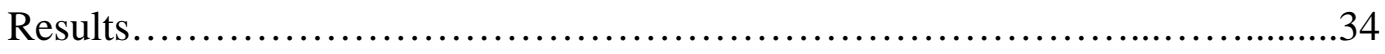

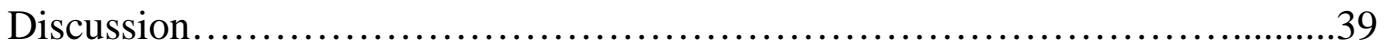




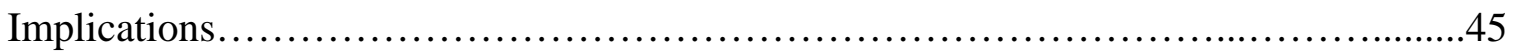

Literature Cited............................................................

Melengestrol acetate as an alternative method to induce molting and the effect on

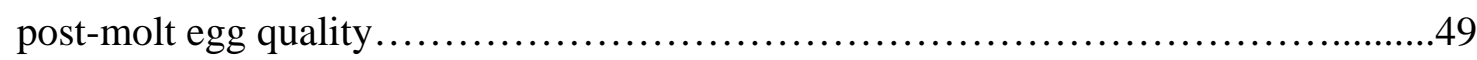

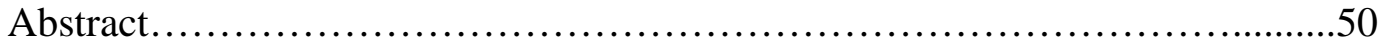

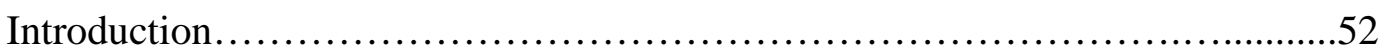

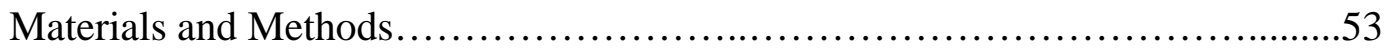

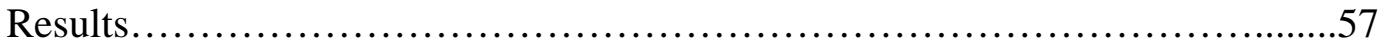

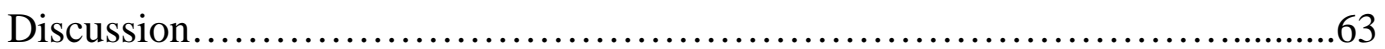

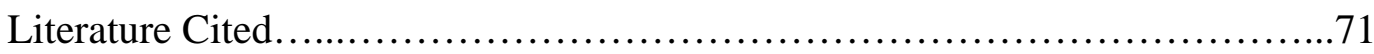

An alternative method to induce molt that addresses hen well-being......................74

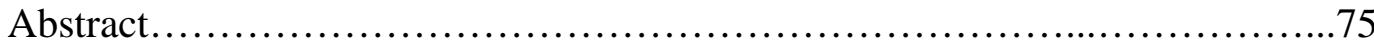

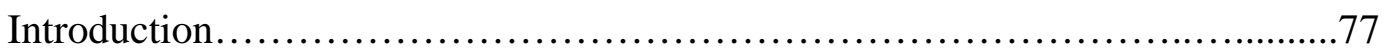

Materials and Methods....................................................

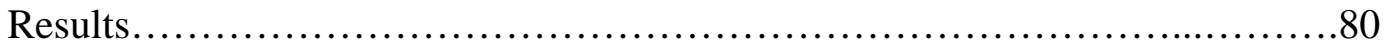

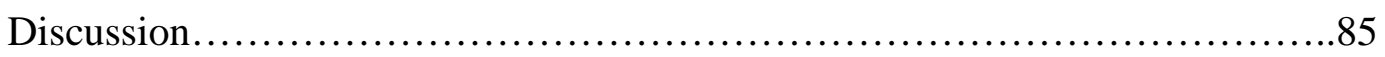

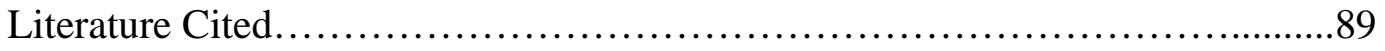

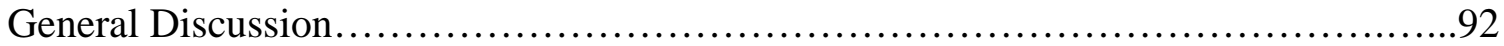

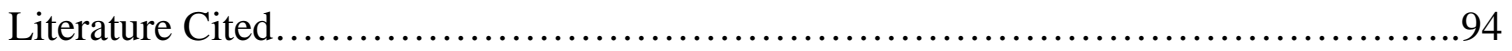




\section{List of Figures}

Figure 1. Daily egg production for hens fed 0, 0.1, 1, 4 and 8 mg of MGA

per hen per day, beginning on day 0

Figure 2. Weight of the ovary with large yellow follicles for hens fed 0,

$0.1,1,4$ and $8 \mathrm{mg}$ of MGA per hen per day, beginning on day

Figure 3. Oviduct length for hens fed 0, 0.1, 1, 4 and $8 \mathrm{mg}$ per hen per

day of MGA beginning on day 0

Figure 4. Oviduct weight for hens fed 0, 0.1, 1, 4 and $8 \mathrm{mg}$ per hen per

day of MGA beginning on day 0

Figure 5. Magnum weight for hens fed 0, 0.1, 1, 4 and $8 \mathrm{mg}$ per hen per day of MGA beginning on day 0

Figure 6. Shell gland weight for hens fed 0, 0.1, 1, 4 and $8 \mathrm{mg}$ per hen per day of MGA beginning on day 0

Figure 7. Internal egg quality as measured by haugh units (\%) for eggs laid..... .58

Figure 8. External egg quality as measured by shell thickness (mm)

for eggs laid

Figure 9. External egg quality as measured by breaking strength (g)

for eggs laid

Figure 10. Return to lay for hens fed $4 \mathrm{mg}$ of MGA per hen per day for varying durations.

Figure 11. Return to lay for hens fed 8 mg of MGA per hen per day for varying durations.

Figure 12. Yolk MGA concentration (ppb) in days following MGA removal from the diet

Figure 13. Yolk MGA and endogenous progesterone concentration in the days following removal of MGA form the diet, graphed relative to the FDA tolerance for MGA in edible tissue.

Figure 14. Total number of pecks performed during the motivation testing on days $0,3,6$ and 9 .

Figure 15. Total number of rewards received during the motivation 


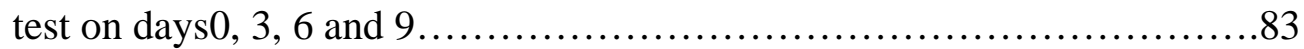

Figure 16. Total distance moved per half hour.................................84 


\section{List of Tables}

Table 1. Preliminary data for testing carriers for MGA..............................31

Table 2. Composition of the experimental and control diets.......................32

Table 3. Composition of the experimental and control diets........................54 


\section{Introduction}

Inducing hens to molt is a method producers in the poultry industry use to get a greater potential return on a flock that is already in their possession (Bell and Weaver, 2002). The increased income is a result of an increase in egg production, egg quality and an extended period of production that results after molting. However, the traditional method to induce hens to molt does not adequately address hen well-being and in the last ten years has started to receive a great amount of public attention and criticism (Gast and Ricket, 2003). The poultry industry as a whole has been trying to develop an alternative method that addresses hen well-being; however, attempts so far have been unsuccessful in addressing hen well-being and achieving consistent post-molt performance (Bell, 2003).

The traditional method to induce molting is accomplished by an extended period of feed withdrawal that lasts about 10 to 14 days. Feed withdrawal can be accompanied by a decrease in lighting and together they may result in a reduction in hen weight or up to 33 percent. Current alternative methods manipulate the nutrient balance in a layer diet, which indirectly disrupts the reproductive cycle. These alternatives include feeding diets with alterations in mineral content (i.e., low calcium, low sodium or high zinc) or feeding a low nutrient density diet (i.e., wheat middlings; Berry, 2003). Although these alternative methods appear to be a simple solution to a feed withdrawal induced, molt because hens still receive some type of feedstuff, they too may result in inadequate hen well-being. These alternatives have been found to increase the incidence of hen paralysis, kidney and adrenal damage and result in dehydration (Douglas et al., 1972; Siegel, 1961). 
Body weight loss is used as an indicator of how effective the molt will be in improving post-molt performance. However, the key component to an effective molt is reversible regression of the reproductive tract and more specifically the secretetory cells that line the oviduct and produce components of the egg (Brake and Thaxton, 1979). The oviduct and secretetory cells are maintained through a complex regulatory pathway known as the, hypothalamic-hypophyseal-gonadal axis, and disruption of this pathway results in a cessation of lay (Dickerman and Bahr, 1989, Adams, 1956). Induced molting by feeding a nutrient imbalanced diet, indirectly affects this pathway and in most cases only results in a reversible regression of some oviduct components, leading to an unpredictable post-molt performance. Other alternatives that have been investigated include treatment of hens with hormones, which would directly affect the hypothalamichypophyseal-gonadal axis while feeding a balanced layer diet (Berry, 2003). However, most of the research conducted on a hormone induced molt requires handling of individual birds that would not be practical on a large scale operation. More research in this area is also needed to determine the effects on post-molt performance and if this method addresses hen well-being concerns.

The need for an alternative method to induce molting that addresses hen wellbeing, results in an increased post-molt performance and is practical for producers is highly sought-after. The traditional feed withdrawal method is unacceptable to the public because it does not take into account hen well-being. Current alternatives are not useful in the industry because they are unpredictable and in some cases, like traditional feed withdrawal, do not adequately address hen well-being and result in unpredictable postmolt performance. Inducing a molt by hormone administration is an area that should be 
more extensively researched because it has the potential to result in an effective alternative to induce a molt that could satisfy consumers and producers. 


\section{Review of Literature}

\section{General Structures and Secretions}

The reproductive cycle of a hen lasts for about 26 hours and includes ovulation, egg formation and oviposition. The large yellow follicles (yolk containing) on the ovary are those selected from a resting pool of primordial follicles to undergo further development. These follicles are arranged in a hierarchy (with five to seven large follicles denoted as F1-F7) with F1 considered the closest to ovulation and upon ovulation the F2 follicle will become the next F1 (Yoshimura and Bahr, 1991). These follicles are maintained and stimulated to ovulate by two gonadotropins, luteinizing hormone and follicle stimulating hormone (Hammond et al., 1981). As in mammals, the hypothalamus of the chicken synthesizes and secretes gonadotropin releasing hormone. Gonadotropin releasing hormone stimulates the release of the two gonadotropins from the anterior pituitary (Imai and Nalbandov, 1978). Luteinizing hormone and follicle stimulating hormone are synthesized in the anterior pituitary while their main site of action is at the large yellow follicles on the ovary. Both gonadotropins function to stimulate the production of sex steroids (Hammond et al., 1981). The two layers of the preovulatory follicle that produce sex steroids are the granulosa cells and the theca cells. The main steroids, secreted by the granulosa cells and the theca cells have different sites of action and affect reproductive function differently. It is the action of these hormones that maintains the reproductive cycle in the hen (Nitta et al., 1991).

\section{Sex Steroid Production}

Sex steroids are produced from the conversion of cholesterol by a number of enzymes, many of which are cytochrome P450 enzymes. Cholesterol must be transported 
into the inner mitochondrial membrane, by steroid acute regulatory protein (i.e., StAR; Johnson et al., 2002) that is regulated by adenylyl cyclase. The binding of follicle stimulating hormone to the follicle stimulating hormone receptor increases the activity of adenylyl cyclase resulting in an increased transport of cholesterol into the inner mitochondrial membrane from the cytoplasm of the cell. Once inside the mitochondria cholesterol is converted to pregnenolone, by the enzymatic action of cytochrome P450 side chain cleavage, which cleaves the six carbon side chain from cholesterol. Pregnenolone then moves into the endoplasmic reticulum where the enzyme $3 \beta$ hydroxysteroid dehydrogenase converts pregnenolone into progesterone. Testosterone is the result of the conversion of progesterone by cytochrome P450 17 $\alpha$-hydroxylase cytochrome/17-20 lyase. Testosterone is converted into estradio1-17 $\beta$ by cytochrome P450 aromatase.

\section{Theca Cells and Estrogen}

The theca cells in the domestic hen synthesize and secrete estradiol $17 \beta$, as well as small amounts of androgen and progesterone, in response to luteinizing hormone (Bahr et al., 1983; Etches and Duke, 1984; Huang et al., 1979; Marrone and Hertelendy 1983). The thecal layer of the follicle contains two distinct cell layers including the theca interna and the theca externa. The theca interna contains the enzymes P450 side chain cleavage and P450 17 $\alpha$-hydroxylase/17-20 lyase and theca interna interstitial cells contain 3 $\beta$ hydroxysteroid dehydrogenase. The theca externa also contain cytochrome P450 17 $\alpha$ hydroxylase/17-20 lyase as well as P450 aromatase (Nitta et al., 1991). Originally it was thought that the the theca cells only to had the enzymes needed to convert progesterone produced in the granulosa cells to androgens and estradiol $17 \beta$ (Huang et al., 1979). 
More recently it has been shown that theca cells have all the enzymes needed to convert cholesterol to estrogen even though theca cells will readily use the available progesterone produced by the granulosa cells (Nitta et al., 1991).

In avian species, estrogen is primarily responsible for stimulating the liver to synthesize and secrete the major yolk proteins (i.e., vitellogenin and apolipoprotein; Deeley et al., 1975; Evans et al., 1987) and support the epithelial cells of the oviduct (Oka and Schimke, 1969). The transcription of the three major yolk proteins, vitellogenin I, vitellogenin II and apolipoprotein II, is regulated by estrogen binding to the estrogen receptor in the liver (Gordon et al., 1988). These estrogen receptors increase in number as the hen gets closer to the start of egg production and the maximum number of receptors are found during production (Evans et al., 1987). Estrogen also stabilizes the mRNA resulting in an increase in the yolk proteins (Gordon et al., 1988). Once these yolk proteins are produced in the liver they are transported to the oocyte, within the follicle, as plasma macromolecules in the blood. A 95-kDa receptor is responsible for transporting vitellogenin and apopolipoprotein across the membrane into the yolk spheres (i.e., storage sites for yolk proteins and the site of postendocytic proteolytic processing of yolk proteins) within the yolk, but the mechanism by which these yolk transporters transport and process yolk proteins is not known (Barber et al., 1991).

\section{Granulosa Cell and Progesterone}

The granulosa layer of the follicle synthesizes and secretes large amounts of progesterone and small amounts of androgens in response to follicle stimulating hormone and luteinizing hormone (Johnson et al., 1987; Ritzhaupt and Bahr, 1987). The concentration of progesterone released from the granulosa cells increases as the follicle 
moves from the bottom of the follicle hierarchy to the F1 position (Etches and Duke, 1984). Progesterone is a product of cholesterol so to produce progesterone the granulosa cells must contain the enzymes needed for its production. Indeed, granulosa cells contain the enzymes, steroid acute regulatory protein, P450 side chain cleavage, and 3 $\beta$ hydroxysteroid dehydrogenase, which are needed for the conversion of cholesterol to progesterone within the granulosa cells. In the small yellow follicles (i.e. F5-F3), follicle stimulating hormone increases the activity of adenylyl cyclase, but as the follicle progresses in the hierarchy (i.e. F2-F1) the sensitivity for follicle stimulating hormone induced activation of adenylyl cyclase is reduced, which is thought to be due to a decrease in follicle stimulating hormone receptors (Ritzhaupt and Bahr, 1987; Johnson and Bridgham, 2001). However, luteinizing hormone binding to its receptor on the granulosa cells will maintain the activity of adenylyl cyclase in the F3-F1 follicles (Calvo and Bahr, 1983).

There are two centers in the hypothalamus in which progesterone can affect the secretion of gonadotropin releasing hormone and therefore of luteinizing hormone. The tonic center is responsible for tonic (i.e. low and continuous) release of gonadotropin releasing hormone which stimulates tonic release of luteinizing hormone that is needed in follicular development. Progesterone has a negative feedback on this center so that as the concentration of progesterone increases the less gonadotropin secreted (Figure 1; Gorski, 1966; Opel, 1979). The surge center is responsible for the luteinizing hormone surge that results in ovulation of the F1 follicle. Progesterone has a positive feedback on this center. At an extremely high concentration progesterone stimulates surge release of 
gonadotropin releasing hormone and therefore surge release of luteinizing hormone leading to ovulation (Imai and Nalbandov, 1978).

\section{Egg Components}

There are several parts to the oviduct each contributing a different component to the egg. The infundibulum is the site where the follicle enters into the oviduct. The magnum contains two main types of cells, those that synthesize protein and those that are ciliated (Kohler et al. 1969). Estrogen stimulates the synthesis of yolk proteins (i.e., ovalbumin, avidin and lysozyme) by tubular gland cells and goblet cells (Oka and Schimke, 1969; Kohler et al. 1969). Under the stimulation of estrogen the ciliated cells that line the lumen of the magnum move the developing egg though the magnum to isthmus. The isthmus is the site where the inner and outer shell membranes are formed before being forced into the shell gland (Bell and Weaver, 2002). The shell gland is the component of the oviduct in which the developing egg spends the majority of time (i.e., 18-20 hours out of a 24-26 hour lay cycle; Bell and Weaver, 2002) and is the site of hard shell formation. Progesterone and estrogen regulate the production of calcium-binding protein (i.e., assists in calcium transfer) by the tubular gland cells in the shell gland. Progesterone stimulates the transfer of calcium by the surface epithelial cells into the shell (Yoshimura and Bahr, 1991). Progesterone also stimulates contraction of the smooth muscle surrounding the shell gland, resulting in expulsion of the fully developed egg. 


\section{Lay Cycle}

While the exact day at which a hen will start laying eggs varies among varieties and individual management practices, the average time from hatching to first lay is about 17 weeks. Production in the poultry industry is measured by the number of eggs produced per hen per day, expressed as a percentage. It takes another three weeks from the start of production to reach $50 \%$ production and an additional three to four weeks to reach peak production. Peak production is when a hen is at the maximum production that will be reached in a single lay cycle. In most cases peak production can be around the mid to upper ninetieth percentile. After reaching peak production the number of eggs laid declines until hens are removed from the flock, or are induced to molt. Another important component of egg production is the internal and external quality of the eggs laid. Internal egg quality is assessed by the size of the air cell, the height and roundness of the albumen and the color of the yolk. When an egg is first laid, the air cell is very small and will increase in size as the egg ages. A standard measure used to assess internal egg quality is Haugh units. Haugh units are the observed albumen quality, which is determined using albumen height and the weight of the egg. Yolk quality is determined by yolk shape, the yolk shadow (i.e., during candling) and the color of the yolk (Bell and Weaver, 2002). External egg quality is determined by shell formation, shell color and shell thickness. Shell formation is encompasses several qualities including, shell strength (i.e., breaking strength), shape of the egg (i.e., for best quality it should be oval) and the smoothness of the shell (i.e., small bumps decrease the value) and the number of natural pores (i.e., a greater number of pore the greater the chances of microbial penetration and will result in increased water loss; Bell and Weaver, 2002). 
The number of eggs produced and the overall quality of the eggs is better during the first lay cycle than consecutive induced cycles (Bell and Weaver, 2002).

\section{Molting}

Hens utilized in table egg production reach peak production at about 22 weeks of age and if not induced to molt will be removed from production due to low production and poor egg quality at about 85 weeks of age (Bell, 2003). A producer can make the decision to induce a molt depending on egg production, egg quality, egg prices, the cost of feed and other factors. Molting a flock will lead to an overall increase in egg quality and extend the productive life of the hen. The most widely used method for inducing a molt includes withdrawing feed and decreasing the duration of light exposure until the hens lose 33\% of their total body weight. This procedure is termed "induced molt". Induced molt by feed withdraw is an easy management tool to increase the return on hens that are already in the possession of the producer. A single molt (i.e., molting is induced only once) will extend production in the same group of hens for an additional 45 weeks, which will increase the time in production up to 130 weeks of age (Bell and Weaver, 2002). Molting also reduces the number of flocks needed in a period of time. For example in a ten year period if flocks are replaced after each cycle a producer will go through 8.4 flocks, compared to 5.7 flocks if hens are molted to produce a second cycle (Bell, 2003).

Inducing a molt not only extends the production time, but it also increases egg quality above that observed prior to molt. Egg weight is increased with consecutive molts compared to egg weight before molt. Albumen quality, grade, shell thickness, egg specific gravity and shell texture will improve to the level expected of the quality 
produced by hens that were only in production for six months (Bell, 2003). The mechanism in which egg quality is increased is not quite understood, but it is speculated that these increases are do to turnover in the epithelial lining of the oviduct which occurs during molting (Brake and Thraxton, 1979).

There are changes in various physiological components of the hen during an induced molt. However, it is the changes in hypothalamic-hypophyseal-gonadal axis that result in the observed increase in egg quality post-molt. Areas in the anterior pituitary where luteinizing hormone and follicle stimulating hormones are synthesized and secreted go through remodeling during a molt. For about the first twenty days of an induced molt these cells are undergoing apoptosis (i.e., programmed cell death) and directly after molt these cells start proliferating generating a new population of cells (Chowdhury and Yoshimura, 2004; Yoshimura et al., 1997). The loss of gonadotropins as a result of the induced molt, results in the loss of support for the follicles leading to atresia of the large follicles on the ovary, and eliminates the growth of small white follicles (Eroschenko and Wilson, 1974). Without the large steroid producing follicles the support for the oviduct is lost and it too will go through regression.

During an induced molt the single layer of epithelial cells that line the oviduct go through hyperplasia and hypertrophy leading to an overall decrease in the surface area of the lumen (Eroschenko and Wilson, 1974). The tubular glands are located throughout the oviduct and are made up of cells that secrete components of the egg (i.e., albumen, inner and outer shell membrane and the hard shell) and are stimulated by progesterone. The tubular glands that line the magnum and isthmus go through regression in response to low progesterone concentrations and as a result there is an increase in the formation of 
connective tissue (Eroschenko and Wilson, 1974, Yu and Marquardt, 1973). When steroidogenic support for the isthmus and shell gland are lost, small lumina fill with cellular fragments formed from degenerated cells (Eroschenko and Wilson, 1974). Induced molt leads to atresia of the yellow follicles on the ovary resulting in increased connective tissue on the ovary (Eroschenko and Wilson, 1974).

Following molt the rejuvenation of the oviduct is described as being similar to the development of the reproductive tract before the onset of lay (Yu and Marquardt, 1973). The development of the oviduct is rapid and is associated with cell hyperplasia. Epithelial cells are undergoing formation and proliferation while the tubular cells increase in mass and number of secretion granules (Yu and Marquardt, 1973).

\section{Molting Methods}

Molting by feed withdrawal is a very practical and economical tool that producers use to increase the potential for flock profit. However, due to public criticism of feed withdrawal as a method to induce molt, it may soon be phased out. Consumers are pressuring large companies to make a stand and not use eggs that are produced as a result of induced molt by feed withdrawal. Large companies, including the McDonalds Corporation which purchases over 1 billion table eggs each year has stated that they will no longer purchase eggs that are produced by hens that have been molted (Gast and Ricket, 2003). Pressure from consumers and the desire by the poultry industry to address hen well-being has resulted in the development of alternative methods to induce a molt. However, if an alternative method is to be used in large scale operations it must be practical and economical for producers. Currently most alternative methods manipulate the balance of required nutrients, which indirectly disrupt the reproductive cycle. These 
alternatives include feeding diet with alterations in mineral content (i.e., low calcium, low sodium or high zinc) or feeding a low nutrient density/unbalanced diet (i.e., wheat middlings; Berry, 2003). Although these alternative methods appear to be a simple solution to a feed withdrawal induced molt they too have downfalls. The post-molt performance that is obtained from these alternatives is not repeatable, in many cases postmolt performance is not improved and these alternatives still do not adequately address hen well-being.

\section{Nutrient Manipulation}

The amount of time needed to completely eliminate or dramatically reduce egg production varies considerably between a feed withdrawal molt and its alternatives. In addition the time from the end for molting to peak production varies compared to the proposed alternatives. Feed withdrawal requires the longest post-molt recovery, even though egg production is eliminated within 10 days, as peak production is not achieved until 91 days from the start of feed withdrawal (Gilbert and Blair, 1975; Bell, 2003). Feeding a low calcium diet (i.e., less than $5 \%$ of the daily recommended level; NRC, 1994) led to a 66\% decrease in production within 14 days (Douglas et al., 1972). After 21 days or 28 days on treatment, egg production was completely abolished (Nevalaine, 1969; Douglas et al., 1972). Egg production following the return to a normal calcium diet took up to 21 days to reach $30 \%$ to $100 \%$ of the egg production of the controls (Nevalaine, 1969; Douglas et al., 1972). Feeding a corn and soybean based diet without additional sodium (i.e., low sodium diet containing approximately $20 \%$ of the sodium in control diets) led to varying degrees of lay cessation. In some situations, egg production was eliminated within 21 days (Nesbeth et al., 1976b) while in other cases feeding a low 
sodium diet for four weeks only led to a $90 \%$ reduction in egg production (Dilworth and Day, 1976). Upon return to a balanced sodium diet egg production increased to control levels within two weeks (Nesbeth et al., 1976a). Feeding a diet containing 150 times the amount of the daily recommended zinc content (NRC, 1994; in the form of zinc acetate or zinc oxide; i.e., high zinc diet), eliminated egg production within one week. Within two weeks of being returned to a diet balanced to the normal zinc content the level of egg production was equal to controls (Shippee et al., 1979; Berry and Brake, 1987).

These alternatives do result in a quick molt (i.e., from the start of molt to peak production post-molt), but in most cases they do not result in an increase in egg quality in all components, do not result in a synchronous return to lay and rarely do they address hen well-being. Low calcium diets were not effective in improving egg specific gravity (i.e., a measure of shell quality) post treatment, caused paralysis in some hens and increased mortality up to $20 \%$ compared to hens maintained on a diet meeting the hen's requirements (Douglas et al., 1972). Using a low sodium diet as an alternative to induce molt did result in increased egg weight and egg specific gravity above that of the control; however, feeding a low sodium diet led to a 59\% decrease in feed intake, which resulted in a $19 \%$ loss in hen body weight (Nesbeth et al., 1976b). Feeding a low sodium diet has been found to result in kidney and adrenal damage (Siegel, 1961). Feeding a high zinc diet decreased feed intake by at least 50\% depending on the concentration of zinc in the diet (Shippee et al., 1979; Berry and Brake 1987), and there were no improvements in egg specific gravity, internal egg quality or egg production between hens induced to molt by a high zinc diet (Shippee et al., 1979). 
Wheat middlings are a low energy and low protein feedstuff (i.e., much different than just removing one feed ingredient) that when used as an alternative does not supply the nutrients needed by hens for egg production, but provides bulk feedstuff to increase gut fill. The diet used for molting is approximately $94 \%$ wheat middlings which has been shown to eliminate production or lead to a 92\% reduction after 28 days (Biggs et al., 2003; Biggs et al., 2004). A wheat middlings diet results in an immediate decrease in lay, but did not result in increased egg production, improved internal egg quality or egg specific gravity after molt as compared to those molted by feed withdrawal (Biggs et al., 2003; Biggs et al., 2004). Hens receiving a wheat middling diet lost on average $13 \%$ of initial body weight during treatment, which was due to a $30 \%$ reduction in feed intake (Biggs et al., 2003; Biggs et al., 2004).

\section{Hormone Induced Molt}

Alternative methods that induce molting by altering the nutrient content of a balanced layer diet result in molting by indirectly disrupting the hypothalamichypophyseal-gonadal axis (i.e., via lack of nutrients). Other methods work by directly manipulating the hypothalamic-hypophyseal-gonadal axis (i.e., gonadotropin releasing hormone agonist, anti-gonadotropin and progestin) to induce a molt. The release of gonadotropin releasing hormone, results in the release of luteinizing hormone and follicle stimulating hormone and without these two gonadotropins the follicles will undergo regression and stop producing the steroids needed to maintain the oviduct, resulting in regression of the oviduct. Constant infusion of a gonadotropin releasing hormone agonist will down regulate the gonadotropin releasing hormone receptor in the anterior pituitary gland and therefore remove the stimulus for secretion of the two gonadotropins, which 
will result in follicle regression. The elimination of progesterone leads to regression of the oviduct and cessation of lay. When compared to hens induced to molt with feed withdrawal those treated with a gonadotropin releasing hormone agonist reached the same production level post treatment, but did so twelve days quicker. Furthermore, hens lost less body weight than those on the feed withdrawal method (Dickerman and Bahr, 1989). Feeding a diet with Enheptin an anti-gonadotropin compound, resulted in a delayed onset of lay, limiting the development of the reproductive tract (Pino and Hudson, 1953). Daily administration of follicle stimulating hormone and luteinizing hormone resulted in a decrease in egg production; however, when progesterone was given at the same time egg production was eliminated almost immediately (Juhn and Harris, 1956).

Progesterone is the main sex steroid in the chicken and manipulating the the concentration of progesterone will result in a disruption of the lay cycle. Feeding progesterone dissolved in propylene glycol for five weeks, at $110 \mathrm{mg} / \mathrm{kg}$ or $220 \mathrm{mg} / \mathrm{kg}$ (11 or $22 \mathrm{mg}$ per hen per day based on $0.1 \mathrm{~kg}$ feed intake per day), resulted in a steady decline in egg production to $20 \%$ and $15 \%$, respectively, without causing weight loss in the hens (Adams, 1956). Injecting $40 \mathrm{mg}$ of progesterone caused a cessation of egg production within two days (Adams, 1955), while administration of $20 \mathrm{mg}$ of slowly absorbed progesterone caused a cessation of egg production within 14 days (Shaffner, 1954) and an intramuscular injection of 0.5 or $1 \mathrm{mg}$ of progesterone every day for seven days practically eliminated egg production (Gabuten and Shaffner, 1954). 


\section{Assessing Hunger}

Feed restriction is a management tool used in some animal industries to manipulate the productivity of the breeding stock. In the pork industry gestating sows are placed on a restricted diet to limit weight gain and fat deposition. This increases their reproductive performance after their pigs are weaned (Van den Brand et al., 2000). In the poultry industry, broiler breeders and replacement layers are placed on dietary restrictions to limit weight gain prior to sexual maturity (Roberts et al., 1997; Hocking et al., 1993). The well-being issues that arise during periods of feed restriction are difficult to assess because the state of an animal's well-being has to be inferred. Researchers have utilized several techniques to attempt to assess the level of hunger by characterizing changes in physical activity and by determining an animal's motivation to obtain feed (Roberts et al., 1997; Hocking et al. 1993; Savory et al., 1993; De Jong et al., 2002).

\section{Stereotypies}

The relative time an animal spends performing various activities is related to the animal's state of well-being. Stereotypies are classified as repetitive abnormal behaviors associated with reduced animal well-being, and are used in many cases to assess wellbeing (Barnet and Hemsworth, 1990). Several stereotypies including spot pecking, pacing and pacing are associated with hunger and frustration.

\section{Hen Well-being}

Hens subjected to feed restriction were found to spend a larger portion of their time drinking, and overall consumed more water than hens on an ad libitum diet (Preston, 1987; Hocking et al., 1993; DeJong et al., 2002). Restriction of feed from hens led to an increase in the amount of time they spent pecking and scratching the floor as well as the 
frequency of preening (Preston, 1987; Hocking et al., 1993). Spot pecking of the side of the cage has been associated with frustration and increases when hens are feed restricted (Preston, 1987; Hocking et al., 1993).

\section{Motivation Testing}

Operant conditioning is a research technique that can be used to determine an animal's wants and preferences. It is defined as an animals ability to learn based on the an animal's wants within its environment. (Ewing et al., 1999). Examples of using operant conditioning as a research tool is when an animal learns that performing a specific task results in a wanted response. This relates to the idea that during testing those animal that are more motivated to obtain the reward will work harder. Rewards for chickens might include increased lighting, larger pen size or additional feed, but for swine it might be greater social interaction or additional feed (Prescott and Wathes, 2002; Lawrence and Illius, 1989). The number and time interval in which rewards are awarded will depend on the type of reinforcement schedule that is used in the experiment. Examples of reward schedules include; fixed ratio reinforcement, when an animal must perform a fixed number of tasks to obtain the reward, or progressive ratio reinforcement, when the subject must perform an increased number of tasks to receive the next reward. Motivation testing has been used to assess a state of well-being in the in domestic livestock. However most of the testing has been done in swin e and more recently using poultry.

\section{Swine}

Operant conditioning has become a valuable tool to assess the well-being of pigs that are maintained under commercial practices. For example, in the industry pigs are 
placed on feed restriction to limit growth prior to sexual maturity which allows pigs to remain in the breeding population for a longer period of time. Testing the motivation of these animals to obtain feed provides some assessment on an animal's well-being. Feed restricted boars are motivated to obtain feed and increasing the restriction results in an increased motivation to obtain feed (i.e., increase the number of operant response) while boars fed ad libitum are less motivated to obtain the reward and will stop performing the task (Lawrence and Illius, 1989; Lawrence et al., 1989). Pregnant sows provided with only $60 \%$ of a daily ration were considered very hungry because they will actually work hard enough to result in an energy deficit (Huston, 1991). Other studies have looked at the effects of adding high fiber bulk to the diet to allow for complete gut fill. It has been determined that increasing the density of the diet without increasing the nutrients does not decrease the pigs' motivation to obtain feed (Lawrence et al., 1989; Roberts et al., 1993; Roberts et al., 1997). It is not the bulk of the diet that stimulates a pig's motivation to eat, but the quality of nutrients and energy that is provided. If the bulk diet is fed and supplemented with nutrients then the motivation of pigs to obtain feed will decrease (Lawrence et al., 1989; Roberts et al., 1993; Roberts et al., 1997).

\section{Poultry}

In the commercial poultry industry broiler breeders are placed on a feed restriction to limit the weight at sexual maturity, which can result in a $65 \%$ lower body weight that would be reached if birds were fed ad libitum. Broiler breeders that were feed restricted (i.e., a level of restriction implemented in the industry) had a greater motivation to obtain additional feed in a 15 minute period of access compared to birds that were on an ad libitum diet because these birds were not receiving enough nutrients 
per day to eliminate hunger. If feed restriction is more severe, then the motivation increases (Savory et al., 1993). Adding bulk to the diet did not result in a decrease in the bird's motivation to obtain feed when weight was not included as a covariate (Savory and Lariviere, 2000).

\section{Physiology of Hunger}

Feed intake is controlled by a complicated mechanism that is always changing because several different signals are required to stimulate hunger or satiety. For this reason more than one method should be used to test hunger. There are several known neurohormones and peptides that are synthesized and secreted in the brain and gastrointestinal tract during periods of satiety and hunger. Characterizing the synthesis and secretion of these hormones provides a second indicator to characterize hen hunger in addition to testing their motivation to obtain feed.

There are two main centers in the brain that are responsible for determining hunger and satiety. An animals is hungry if it has a desire or need for feed and when it is completely satisfied and full it is at a point of satiety. Hunger is determined in the lateral portion of the hypothalamus (i.e., hunger center) and satiety is determined in the ventromedial portion of the hypothalamus (i.e., satiety center). Each center receives inputs from the gastrointestinal distension, hormones and nutrient absorption and each component is necessary for the release of neurohormones (Guzwiller et al., 2004). Gastrointestinal distension is one of the most important factors that are needed to reach a state of satiety, but to reach a complete state of satiety it must be together with nutrient absorption (Guzwiller et al., 2004, Kral and Rolls, 2004). Nutrient absorption stimulates 
the release of gastrointestinal hormones glucagon-like peptide 1 (GLP-1), ghrelin, and Neuropeptide Y.

These gastrointestinal peptides transmit satiety or hunger signals to the brain either by the vagal nerve or through the blood (Koda et al., 2005). The binding of these peptides to their respective receptors results in the activation of neurons in the hunger and satiety centers resulting in production of neurohormones. Neuropeptide $\mathrm{Y}$ is secreted from the lateral hypothalamus and from paraventricular nuclei of the brain and is a major factor in stimulating feeding behavior. As the concentration of Neuropeptide Y increases as feed deprivation increases (Dube et al., 1988) and there is dose dependent increase in feed intake, so as Neuropeptide Y increases feed intake increases (Stanely and Leibowitz, 1985). Neuropeptide Y plays an important role in the regulation of feeding behavior by stimulating feeding. Cholecystokinin is released from the satiety center of the brain at times of feeding and its secretion will result in the termination of feeding and feeling of satiety within the animal (Moran, 2004). 


\section{Statement of the Problem}

Molting in the poultry industry has been used for many years to increase egg quality, egg production and to extend the productive life of a hen. The traditional method of molting, that has been utilized since the industry started molting, includes an extended period of feed withdrawal that usually lasts about 10 to 14 days or until the hens lose $33 \%$ of their body weight. However, with increasing concerns for hen well-being during molting the traditional method will soon be phased out, and replaced with a more hen friendly method.

An alternative method to induce molting in hens is essential if the industry is going to continue to molt as a means of increasing the profit return on a flock of hens. Consumer concerns about hen well-being during molting has already started to make an impact on consumer based companies. In response to consumer demand, McDonald's Corporation (purchaser of over 1 billon eggs each year) made a statement that they will no longer buy eggs that are produced by hens that have been molted by feed withdrawal (Gast and Ricket, 2003). The poultry industry is working hard to find an alternative that addresses these well-being concerns and is suitable for use in the industry, but the problem still remains.

Current alternative methods thus far are not much better than molting by traditional feed withdrawal. These alternatives do not provide a balanced diet. The alternatives include feeding diets with alterations in mineral content (i.e., low calcium, low sodium or high zinc) or feeding a low nutrient density diet (i.e., wheat middlings; Berry, 2003). These alternatives do not adequately address hen well-being even though hens are provided some type of feedstuff. Not only have these alternatives been found to 
cause hen paralysis, kidney and adrenal damage, hen dehydration and hen weight loss (Berry, 2003; Douglas et al., 1972; Lumijarvi et al., 1966; Seigle, 1961) but the daily nutrients recommended by the National Research Council are not met (NRC, 1994). From the producer's perspective these alternatives result in unpredictable post-molt performance and have only been considered because they are a first step in finding a replacement for traditional feed withdrawal induced molt.

It has been shown that reproductive hormones can alter the lay cycle of a hen and some situations result in an induced molt while hens are maintained on a balanced layer diet. However, the main method of administration is through subcutaneous injection, which requires the handling of individual birds. Because of the impracticality of handling individual hens the research conducted on a hormone induced molt is limited. The limited amount of research that has been conducted looking at the physiological aspects of molting was focused on feather molt, egg production decline and weight loss. The components of molting such as post-molt performance and the effects on hen wellbeing have been ignored in the literature and need to be addressed if an alternative method is going to become the industry standard.

The idea of the current experiments were to determine if an orally active progestin, melengestrol acetate (MGA), would be an effective method to induce molting that addresses hen well-being during and after molt. MGA can easily be administered to a large population because it is orally active and can be included in a balanced layer diet. Hens could be fed to meet nutrient demands throughout the molting process, which would address the concerns brought about by other methods in that there is a nutrient deficiency that results in hen weight loss. If feeding MGA can effectively lead to a 
reversible regression of the oviduct then it may also lead to an increase in egg quality post-molt. 
Melengestrol acetate as an alternative method to induce molting ${ }^{1,2}$

\author{
J.M. Koch ${ }^{3}$, D.C. Lay Jr ${ }^{4}$., J.S. Moritz ${ }^{3}$ and M.E. Wilson ${ }^{3,5}$ \\ ${ }^{3}$ Division of Animal and Veterinary Science, Davis College of Agriculture, Forestry and \\ Consumer Science, West Virginia University Morgantown, West Virginia \\ ${ }^{4}$ USDA-ARS Livestock Behavior Research Unit, Purdue University, West Lafayette, \\ Indiana
}

${ }^{1}$ This work is published with the approval of the Director of West Virginia Agriculture and Forestry Experiment Station as scientific paper. This project was supported by a USDA-ARS Specific Cooperative Agreement Agr \#58-3602-1-172 and Hatch project 321 (NE 161). Disclaimer: The mention of trade names or commercial products in this article is solely for the purpose of providing specific information and does not imply recommendation or endorsement by the U.S. Department of Agriculture.

${ }^{2}$ The authors would like to thank George Siedel for assistance with the statistical analysis ${ }^{5}$ Correspondence: G048 Agricultural Sciences Building (phone: (304) 293-2406 ext. 4425; fax: (304) 293-2232; email: mwilso25@wvu.edu). 


\begin{abstract}
Induced molting is used to increase egg quality, egg production and to extend the productive life of the hen. Traditionally, molting is accomplished by an extended period of feed withdrawal accompanied by a decrease in lighting. The traditional method to induce molt has been criticized for not addressing hen well-being and current alternatives described thus far have resulted in poor post-molt performance and inadequate hen wellbeing. Molting leads to regression of large yellow follicles on the ovary causing loss of steroidogenic support for the oviduct, ultimately leading to cessation of lay.

Melengestrol acetate (MGA), an orally active progestin, may decrease gonadotropic support for the ovary, resulting in loss of steroidogenic support for the oviduct while hens are maintained on a balanced layer diet. Hyline W-36 laying hens at 40 weeks of age were fed 0, 0.1, 1, 4 or 8 mg MGA per hen per day in a balanced diet for 28 days and then returned to a normal diet. Four birds on day 0 and 4 birds per treatment on days 1 , $2,4,8,12,16,20,24,28,32,36,40$ and 44 were euthanized. The weight of the ovary with large yellow follicles, magnum, shell gland and the length and weight of the intact oviduct were determined. A decrease in egg production was observed in those groups receiving 4 and $8 \mathrm{mg}$ of MGA, until removal of MGA from the diet at day 28. After day 28, egg production increased to the production level of hens fed either $0,0.1$ or $1 \mathrm{mg}$ MGA which was maintained throughout the experiment. The weight of the ovary with large yellow follicles, the oviduct, the magnum, the shell gland and the length of the oviduct were unchanged throughout the experiment in the 0, 0.1 and $1 \mathrm{mg}$ MGA groups. However, the 4 and $8 \mathrm{mg}$ of MGA groups had a dramatic decrease $(\mathrm{P}<0.05)$ in the weight of the ovary with large yellow follicles, the oviduct, the magnum, the shell gland
\end{abstract}


and the length of the oviduct until day 28. Recrudescence of the large yellow follicles as well as rejuvenation of the oviduct and its major components the magnum and shell gland in the 4 and 8 mg MGA groups occurred by day 44 . Melengestrol acetate, when fed to hens in a balanced layer diet, can cause regression of large yellow follicles, leading to loss of steroidogenic support for the oviduct. Removal of MGA led to recrudescence of large yellow follicles, leading to a return of the steroidogenic support for the oviduct and return to lay.

Key Words: Chicken, Molting, Melengestrol Acetate, Well-being 


\section{Introduction}

Laying hens are induced to molt to increase egg quality, egg production and extend the productive life of the hen. The predominant management practice to induce a molt requires an extended period of feed withdrawal, often accompanied by reduced lighting and limited water access. Feed withdrawal induced molting has received public criticism concerning the well-being of the hen, leading the United Egg Producers and others (i.e. McDonalds corporation which purchases over 1.5 billon eggs per year) to explore acceptable alternatives (Gast and Ricket, 2003). Current alternatives to feed withdrawal induced molting include feeding diets with altered mineral composition (i.e., low sodium, low calcium or high zinc) or low nutrient density (i.e., high wheat middling inclusion; Berry, 2003) that do not provide the daily nutrient requirements. These alternatives do not reliably improve post-molt egg quality, and in some cases have caused paralysis of the hen, liver, kidney and adrenal gland damage, resulting in dehydration and increased mortality (Berry, 2003; Douglas et al., 1972; Lumijarvi et al., 1966; Seigle, 1961).

An alternative to feed withdrawal induced molt that addresses hen well-being, post-molt performance and practical application is needed. An alternative method could be developed through the well established understanding of hen reproductive physiology. Injecting progesterone into hens has been shown to cause a cessation of lay within 10 days (Adams, 1956; Schaffner, 1954; Gabuten and Shaffner, 1954). However, injecting progesterone into individual hens would not be practical application. A practical method would have to be easily administered to thousands of hens simultaneously, such as the use of an orally active progestin. Such an approach would allow hens to be maintained 
on a balanced layer diet that met daily nutrient requirements, thus addressing hen wellbeing, potentially decreasing morbidity and mortality, while at the same time effectively inducing a molt. Therefore, the objective of this experiment was to determine a dosage of an orally active progestin, melengestrol acetate (MGA), that would down regulate the hypothalamic-pituitary-ovarian axis and lead to reversible regression of the large yellow follicles and the oviduct, causing a temporary reduction in egg production.

\section{Materials and Methods}

\section{Preliminary Studies}

A preliminary experiment was conducted to determine which carrier of MGA, either soybean hulls (440 mg MGA/kg) or propylene glycol (1100 mg MGA/kg), would be more palatable, and if a hen could consume enough carrier in one day to meet the maximum dosage (8 mg per day) proposed for the subsequent experiments. To determine the appropriate, carrier thirty-two hens were divided into two groups and fed either a diet containing $33 \%$ soybean hulls or $13.5 \%$ propylene glycol. Hen weight, egg production and egg weight were determined for one week prior to the start of the preliminary study when hens were fed a standard layer ration (Table 1). During the second week of the preliminary experiment hens were fed either soybean hull or propylene glycol containing diets and hen weight, egg production and egg weight were determined (Table 1). The preliminary experiment demonstrated that hens would consume both carriers. Propylene glycol was used in the subsequent experiment because of its smaller required inclusion rate in order to facilitate formulating a balanced layer diet. To properly formulate a balanced layer diet, the metabolizable energy of propylene glycol for laying hens needed 
to be determined. Therefore, hens $(\mathrm{n}=5)$ were placed in individual metabolism cages and acclimated for two weeks before being placed on a diet containing $30.0 \%$ propylene glycol, 57.7\% ground corn, 9.00\% limestone, 3.00\% defluorniated phosphate, $0.25 \%$ vitamin and mineral premix and $0.09 \%$ sodium chloride. Hens were fed the diet for three days during which time feed intake and the mass of excreta were recorded. The energy content of both feed and excreta were determined via bomb calorimetery (A Parr 1266 bomb calorimeter, Preiser Scientific Inc., Moline, Illinois). The experimental estimate for metabolizable energy of propylene glycol was $3454 \mathrm{kcal} / \mathrm{kg}$ using 3,350 kcal/kg for the metabolizable energy of corn (NRC, 1994). In order for a hen to receive $8 \mathrm{mg}$ of MGA (International Nutrition, Omaha, Nebraska) per day (based on 100g per day intake) diets were formulated to contain 7.27\% propylene glycol (Table 2). 
Table 1. Preliminary data for testing carriers for MGA.

\begin{tabular}{lcccccc} 
& \multicolumn{2}{c}{$\begin{array}{c}\text { Hen Weight } \\
(\mathrm{kg})\end{array}$} & \multicolumn{2}{c}{$\begin{array}{c}\text { Egg Production } \\
(\# / \text { week })\end{array}$} & \multicolumn{2}{c}{$\begin{array}{c}\text { Egg Weight } \\
(\mathrm{g})\end{array}$} \\
\cline { 2 - 7 } Diet Additive & Week 1 & Week 2 & Week 1 & Week 2 & Week 1 & Week 2 \\
\hline $\begin{array}{l}\text { 33\% Soybean Hauls } \\
(\mathrm{n}=16)\end{array}$ & $1.64 \pm .06$ & $1.17 \pm .05$ & 33 & 36 & $69.1 \pm 1$ & $69 \pm 1$ \\
$\begin{array}{l}\text { 13.5\% Propylene glycol } \\
(\mathrm{n}=16)\end{array}$ & $1.79 \pm .05$ & $1.80 \pm .05$ & 35 & 44 & $70 \pm 1$ & $70 \pm 2$ \\
& & & & & & \\
\end{tabular}


Table 2. Composition of the experimental and control diets.

\begin{tabular}{|c|c|c|}
\hline Component & Experimental Diet & Control Diet \\
\hline $\mathrm{Kcal} / \mathrm{kg}$ & 2882 & 2882 \\
\hline Protein (\%) & 17.41 & 17.41 \\
\hline Corn (\%) & 48.12 & 57.62 \\
\hline Soybean (\%) & 27.00 & 27.00 \\
\hline Limestone & 9.20 & 9.14 \\
\hline Propylene Glycol (\%) & 7.27 & - \\
\hline Fat (soy oil; \%) & 3.16 & 2.79 \\
\hline Corn Gluten Meal & 2.72 & 1.50 \\
\hline Defluorniated Phosphate (\%) & 1.92 & 1.39 \\
\hline \multicolumn{3}{|l|}{$\operatorname{premix}^{1}(\%)$} \\
\hline Sodium chloride (\%) & 0.20 & 0.21 \\
\hline Methionine (\%) & 0.17 & 0.10 \\
\hline \multicolumn{3}{|l|}{ Calculated Composition } \\
\hline ME (kcal/kg) & 2882.0 & 2882.0 \\
\hline Crude Protein (\%) & 17.38 & 17.38 \\
\hline Methionine (\%) & 0.45 & 0.45 \\
\hline Lysine (\%) & 0.87 & 0.87 \\
\hline Calcium (\%) & 4.20 & 4.20 \\
\hline Available phosphorus (\%) & 0.46 & 0.46 \\
\hline \multicolumn{3}{|c|}{$\begin{array}{l}\text { Supplied per kg of diet: manganese, } 0.02 \% \text {; zinc, } 0.02 \% \text {; iron, } 0.01 \% \text {; copper, } 0.0025 \% \text {; iodine, } \\
0.0003 \% \text {; selenium, } 0.00003 \% \text {; folic acid, } 0.69 \text { mg; choline, } 386 \text { mg; riboflavin, } 6.61 \mathrm{mg} \text {; biotin, } \\
0.03 \mathrm{mg} \text {; vitamin } \mathrm{B}_{6}, 1.38 \mathrm{mg} \text {; niacin, } 27.56 \mathrm{mg} \text {; panthothenic acid, } 6.61 \mathrm{mg} \text {; thiamine, } 2.20 \mathrm{mg} \text {; } \\
\text { menadione, } 0.83 \mathrm{mg} \text {; vitamin } \mathrm{B}_{12}, 0.01 \mathrm{mg} \text {; vitamin E, } 16.53 \mathrm{IU} \text {; vitamin } \mathrm{D}_{3}, 2133 \mathrm{ICU} \text {; vitamin } \\
\text { A, } 7716 \mathrm{IU}\end{array}$} \\
\hline
\end{tabular}




\section{Experiment}

Hy-Line $\mathrm{W}$-36 laying hens $(\mathrm{N}=264)$ at 40 weeks of age were used for the experiment. All hens were housed three per cage with $186 \mathrm{~cm}^{2}$ of floor space per bird and exposed to 18 hours of light per day. Birds were fed a corn and soybean meal based diet, balanced to meet NRC requirements (Table 2; NRC 1994) and provided ad libitum access to water for 18 weeks before the start of the experiment. Eggs were collected and counted daily. All procedures involving animals were approved by the West Virginia University Animal Care and Use Committee.

Hens were randomly assigned to receive $0,0.1,1,4$ or 8 mg of MGA per day in a balanced diet. From day 0 until day 28, all groups were fed their respective diets, and then were returned to a balanced layer diet containing no propylene glycol until day 44 . Four hens on day 0 and four hens per treatment per day on days 1, 2, 4, 8, 12, 16, 20, 24, 28, 32, 36, 40 and 44 were euthanized. Hens were weighed and tissues (liver, ovary, large yellow follicles, oviduct and its components the magnum and shell gland) were collected, weighed (grams) and measured (oviduct length in centimeters and large yellow follicle diameter in millimeters) when appropriate.

Data for hen weight, ovary weight (both with and without the large yellow follicles), oviduct weight, oviduct length, magnum weight, shell gland weight, and liver weight were analyzed using the GLM procedure of SAS (SAS Inst., Cary, North Carolina) to define regression models with day as a continuous variable and treatment (dosage of MGA) as a categorical variable (model variable=treatment|day|day). Following the regression analysis, T-tests were used to make pair-wise comparisons of the resultant slope coefficients. P-values less than 0.05 were considered significant. 


\section{Results}

There was no change in egg production throughout the 44 days of the experiment in groups receiving either $0,0.1$ or $1 \mathrm{mg}$ MGA per day (Figure 1). However, in groups that received either 4 or $8 \mathrm{mg}$ of MGA per day, egg production decreased rapidly to 52\% and 29\%, respectively (Figure 1). Upon removal of MGA from the diet on day 28, there was a rapid increase in egg production in both the 4 and $8 \mathrm{mg}$ of MGA per day groups (Figure 1).

No difference weight of the ovary without large yellow follicles was detected among treatments $(9.2 \pm 0.1 \mathrm{~g})$. The mass of the large yellow follicles decreased in the 4 and $8 \mathrm{mg}$ per day when compared to the 0, 0.1 and $1 \mathrm{mg}$ of MGA per day groups. After removal of MGA, the mass of the large yellow follicles increased in the 4 and $8 \mathrm{mg}$ of MGA per day groups and were similar to the mass of the 0, 0.1 and $1 \mathrm{mg}$ MGA per day groups by day 44 (Figure 2).

Feeding hens a diet containing either 4 or 8 mg of MGA per day compared to those fed 0, 0.1 and $1 \mathrm{mg}$ per day caused a decrease in oviduct length and weight (Figure 3 and 4). After removal of MGA from the diet on day 28, the weight and length of the oviduct increased to meet controls by day 44 in the 4 and $8 \mathrm{mg}$ per day groups (Figure 3 and 4). Groups receiving either 4 or 8 mg of MGA per day had decreased shell gland and magnum weight compared to the $0,0.1$ or $1 \mathrm{mg}$ per day groups, which maintained shell gland and magnum weight. A steady increase in shell gland weight and magnum weight 


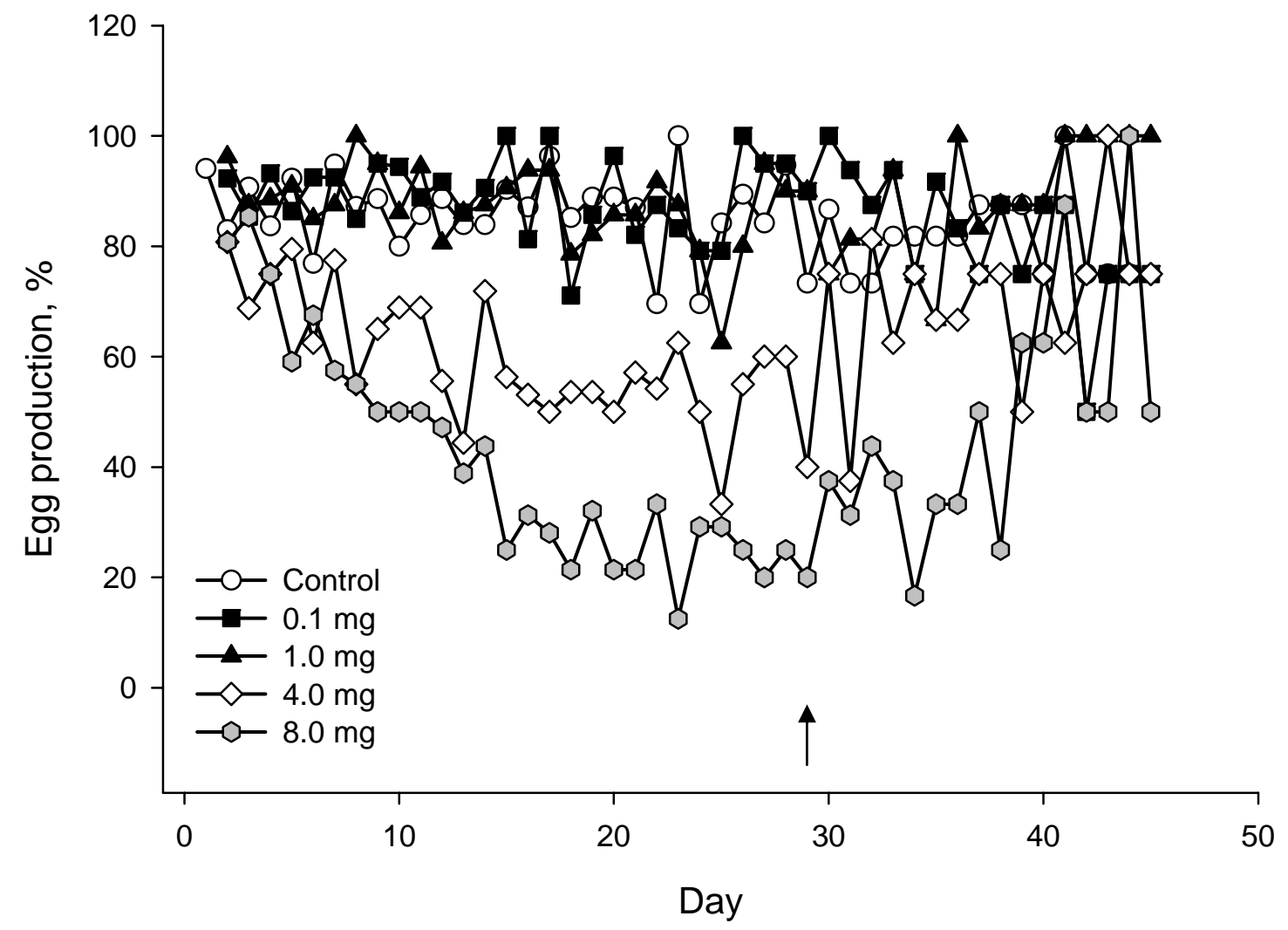

Figure 1. Daily egg production for hens fed $0,0.1,1,4$ and $8 \mathrm{mg}$ of MGA per hen per day, beginning on day 0 . The arrow indicates when MGA was removed from the feed on day 28. 


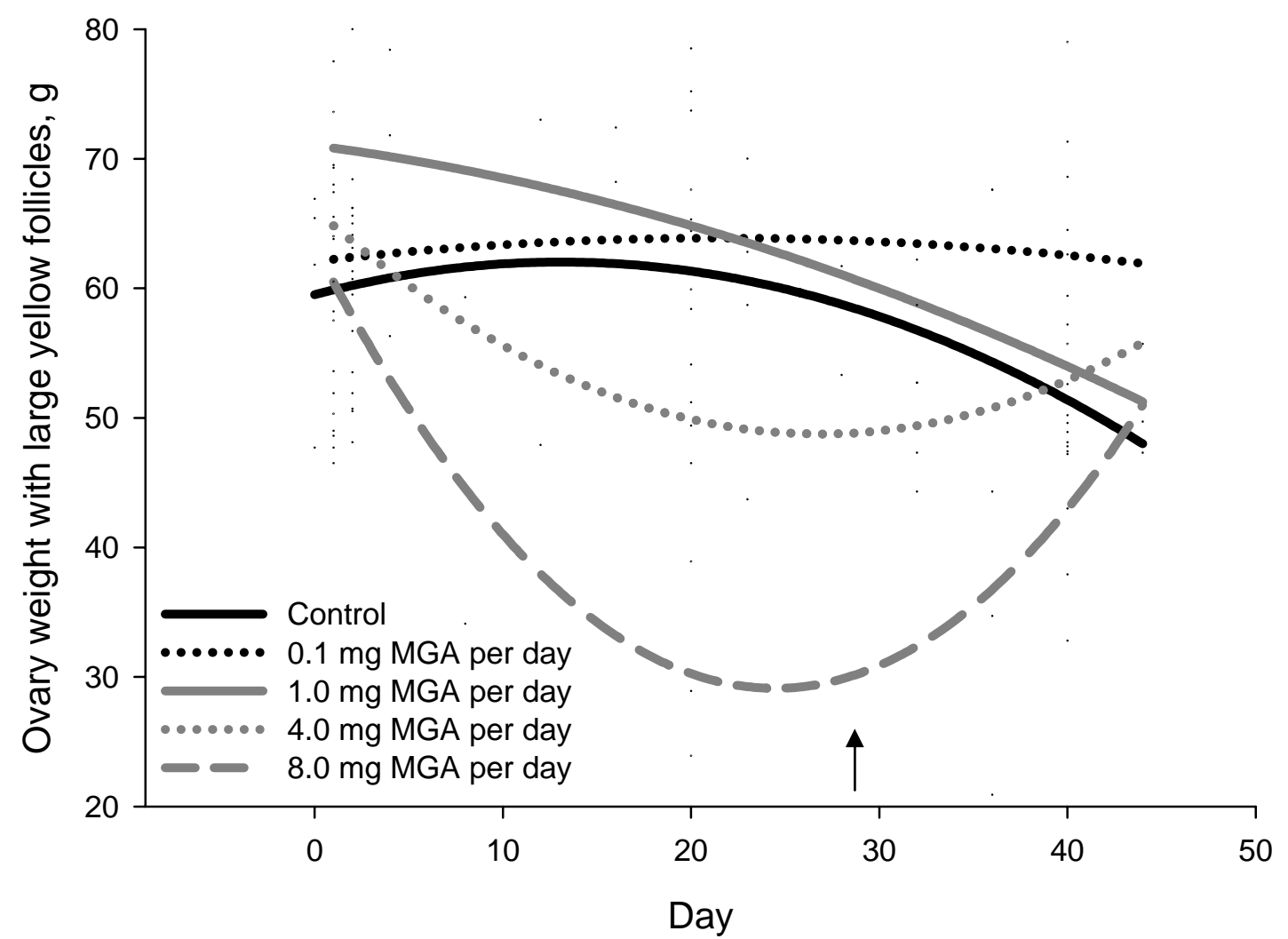

Figure 2. Weight of the ovary with large yellow follicles for hens fed 0, 0.1, 1, 4 and 8 mg of MGA per hen per day, beginning on day 0 . Both linear and quadratic components of the regression lines for 4 and $8 \mathrm{mg}$ per hen per day groups differed from the $0 \mathrm{mg}$ per hen per day group $(\mathrm{P}<0.05)$. Ovary weight without large yellow follicles was not different among groups indicating that the reduction and recovery in weight in the 4 and $8 \mathrm{mg}$ groups was a result of regression and recrudescence of the large yellow follicles. Arrow indicates when MGA was removed from the feed on day 28. 


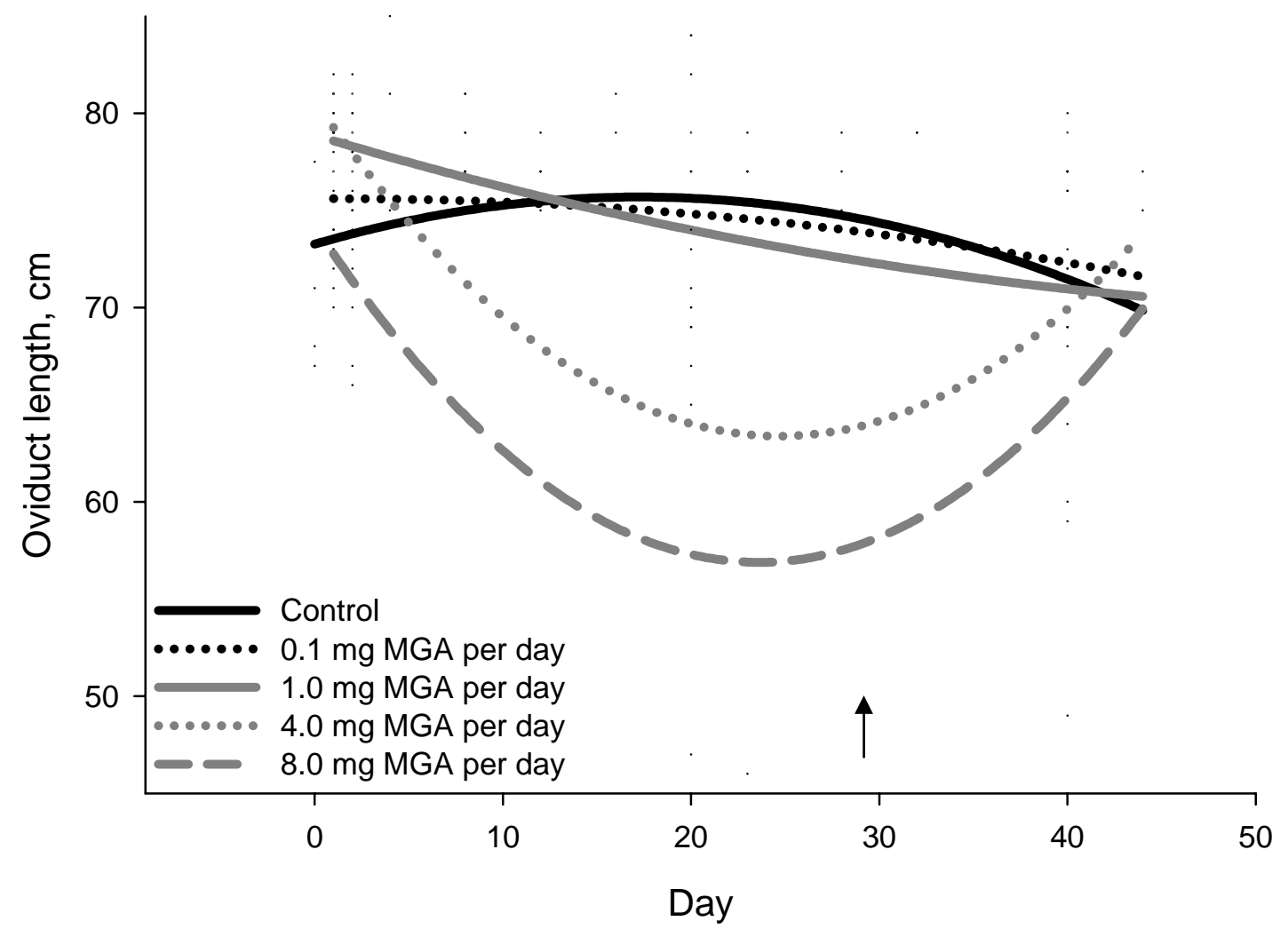

Figure 3. Oviduct length for hens fed 0, 0.1, 1, 4 and $8 \mathrm{mg}$ per hen per day of MGA beginning on day 0 . Both the linear and quadratic components of the regression line for the 4 and $8 \mathrm{mg}$ per hen per day groups differed from the 0,0.1, $1 \mathrm{mg}$ per hen per day groups $(\mathrm{P}<0.05)$. Arrow indicates when MGA was removed from the feed on day 28. 


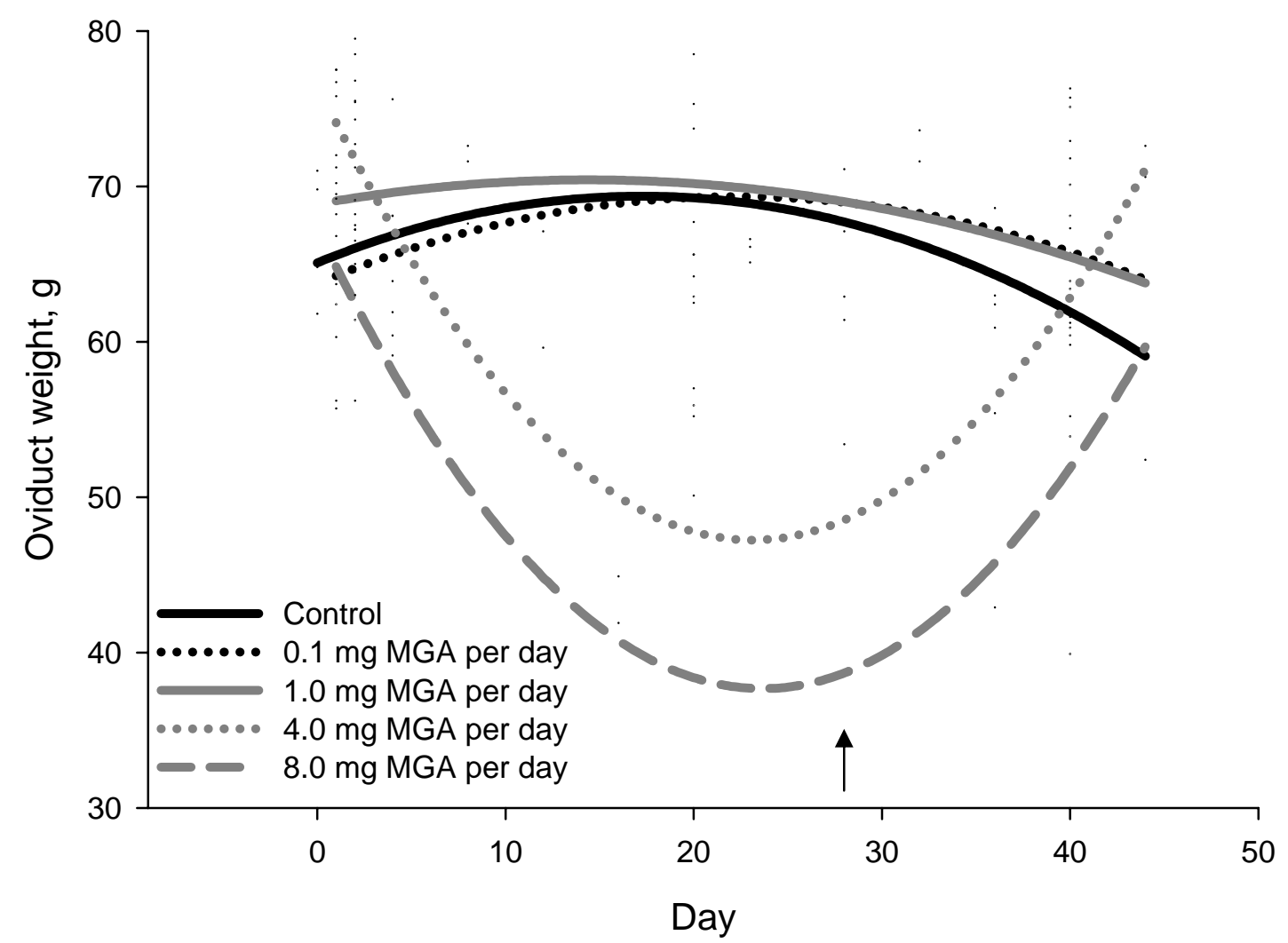

Figure 4. Oviduct weight for hens fed 0, 0.1, 1, 4 and $8 \mathrm{mg}$ per hen per day of MGA beginning on day 0 . Both the linear and quadratic components of the regression line for the 4 and $8 \mathrm{mg}$ per hen per day groups differed from the $0,0.1,1 \mathrm{mg}$ per hen per day groups $(\mathrm{P}<0.05)$. Arrow indicates when MGA was removed from the feed on day 28 . 
occurred in the 4 and $8 \mathrm{mg}$ per day groups after day 28 until reaching the level of the 0 , 0.1 and $1 \mathrm{mg}$ MGA per day groups (Figure 5 and 6). Both hen body weight $(2.47 \pm .04$ $\mathrm{kg})$ and liver weight (45.6 $\pm 0.5 \mathrm{~g})$ were similar among all five treatment groups and did not change throughout the experiment (data not shown). Only one bird died during the experiment, which was a hen receiving 0 mg per day MGA.

\section{Discussion}

Incorporating MGA, an orally active progestin, into a balanced layer diet at a dosage of 4 or $8 \mathrm{mg}$ per hen per day for four weeks led to reversible regression of the reproductive tract. These treatments led to a regression of large yellow follicles on the ovary and a decrease in size and weight of the oviduct resulting in a dramatic decrease in egg production, without a reduction in hen weight. Results of the current experiment, in which an orally active progestin was utilized as a treatment method, are similar to those seen previously, when treating with progesterone (Adams, 1956, Adams, 1955, Shaffner, 155; Shaffner, 1954, Gabuten and Shaffner, 1954). Feeding progesterone dissolved in propylene glycol for five weeks, at $110 \mathrm{mg} / \mathrm{kg}$ or $220 \mathrm{mg} / \mathrm{kg}$ (11 or $22 \mathrm{mg}$ per hen per day based on $.1 \mathrm{~kg}$ feed intake per day), resulted in a steady decline in egg production to $21 \%$ and $10 \%$, respectively, within 28 days, without causing weight loss in the hens (Adams, 1956). Injecting $40 \mathrm{mg}$ of progesterone caused a cessation of egg production within two days (Adams, 1955), while administration of $20 \mathrm{mg}$ of slowly absorbed progesterone caused a cessation of egg production within 14 days (Shaffner, 1954) and an intramuscular injection of 0.5 or $1 \mathrm{mg}$ of progesterone every day for seven days practically eliminated egg production (Gabuten and Shaffner, 1954). In the current experiment 4 or $8 \mathrm{mg}$ per day of MGA resulted in a rapid decline in egg production,. 


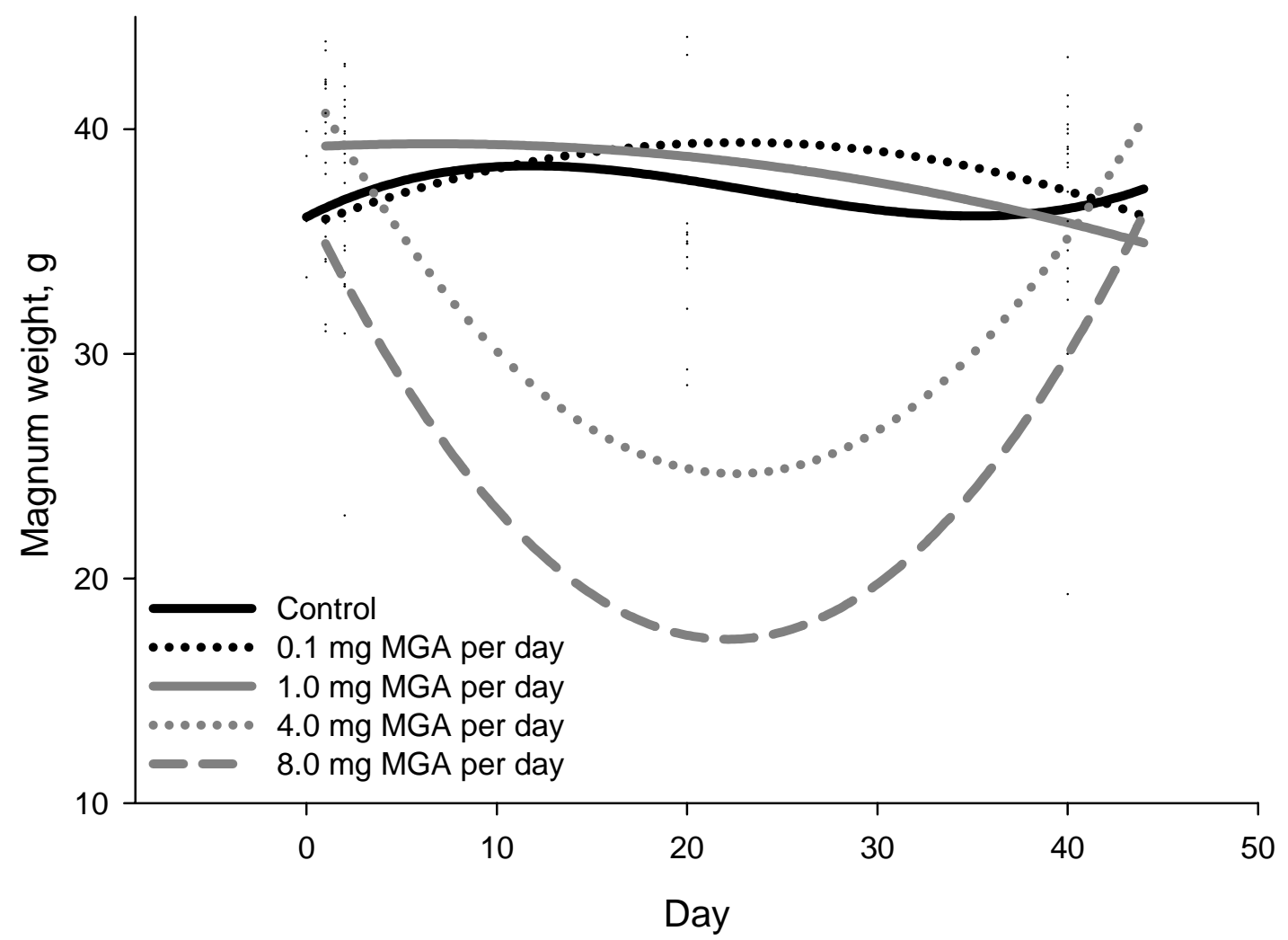

Figure 5. Magnum weight for hens fed 0, 0.1, 1, 4 and $8 \mathrm{mg}$ per hen per day of MGA beginning on day 0 . Both the linear and quadratic components of the regression line for the 4 and $8 \mathrm{mg}$ per hen per day groups differed from the $0,0.1,1 \mathrm{mg}$ per hen per day groups $(\mathrm{P}<0.05)$. Arrow indicates when MGA was removed from the feed on day 28. 


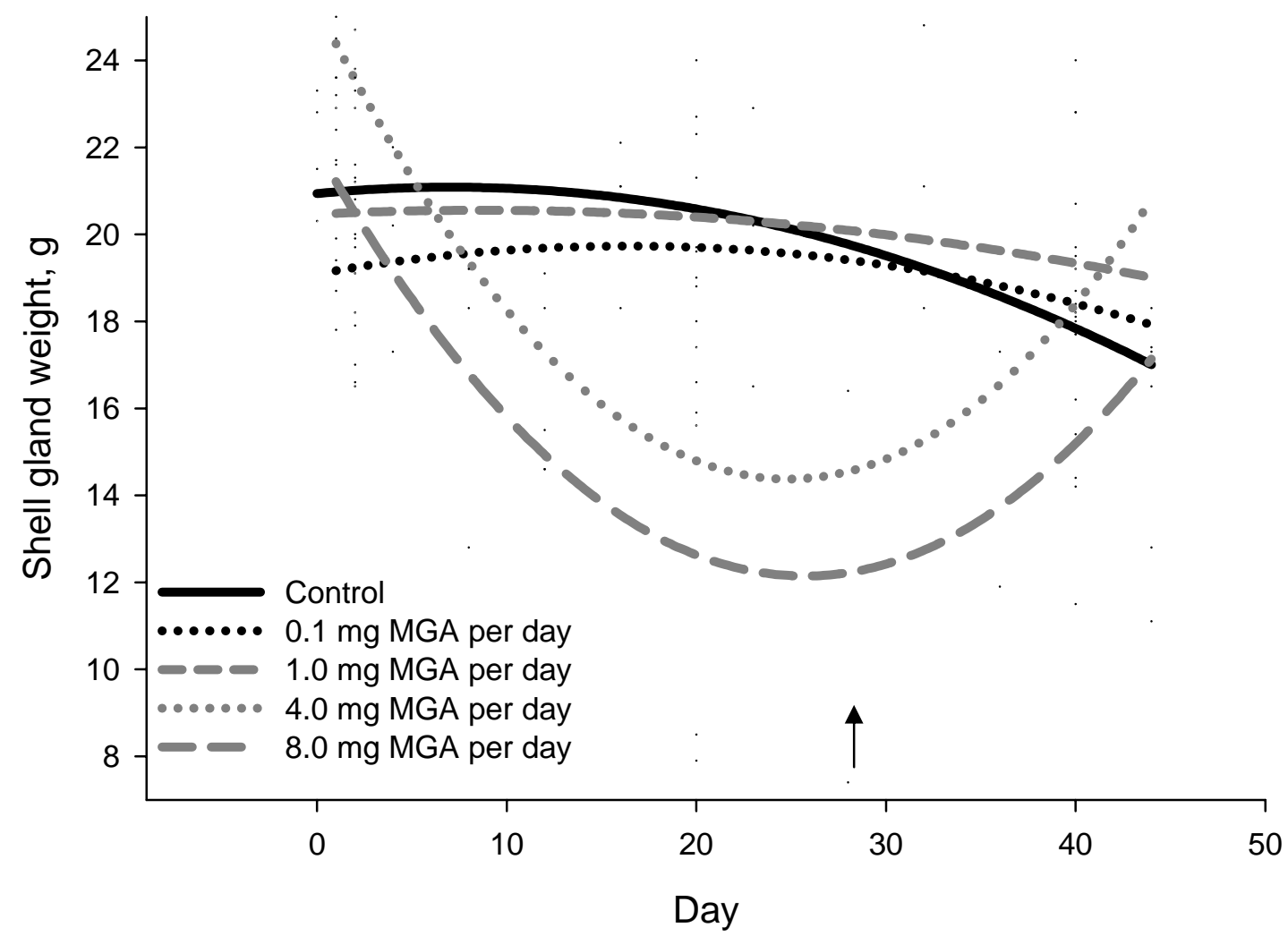

Figure 6. Shell gland weight for hens fed 0, 0.1, 1, 4 and $8 \mathrm{mg}$ per hen per day of MGA beginning on day 0 . Both the linear and quadratic components of the regression line for the 4 and $8 \mathrm{mg}$ per hen per day groups differed from the $0,0.1,1 \mathrm{mg}$ per hen per day groups $(\mathrm{P}<0.05)$. Arrow indicates when MGA was removed from the feed on day 28 . 
which is similar to previous research in which feeding progesterone led to a decrease, but not complete cessation of lay, similar to the effect of injected progesterone

There was no observed decrease in total hen body weight between the control hens and those receiving MGA treatment even though there was an observed decrease in oviduct weight of those receiving 4 or 8 mg of MGA per hen per day compared to those receiving $0,0.1$ and $1.0 \mathrm{mg}$ of MGA groups. This may due to the fact that hens are maintained on a balanced layer diet throughout the experiment and that during molting the nutrients required pre hen decline as production declines.

Alternative methods to induce molt thus far have been unsuccessful in at least one desired outcome; consistent post-molt performance, hen well-being or practicality for the industry. To date, most alternatives are based on feeding diets with alterations in mineral content (i.e. low calcium, low sodium or high zinc) or feeding a low nutrient density diet (i.e., wheat middlings). Feeding a corn and soybean based diet that contains less than 5\% of the required daily dietary calcium (NRC, 1994) led to at least a 66\% reduction in egg production within two weeks and complete cessation after being on treatment for four weeks. Egg production following the return to required calcium level varied from $30 \%$ to $100 \%$ of control production (Douglas et al., 1972; Nevalainen, 1969). Furthermore, low calcium diets were not effective in improving egg specific gravity (a measure of shell quality) post treatment, caused paralysis in some hens and increased mortality up to $20 \%$ compared to hens maintained on a diet meeting the hen's requirements (Douglas et al., 1972). Feeding a corn and soybean based diet that contained no added sodium (i.e., low sodium diet containing approximately $20 \%$ of the sodium requirement; NRC, 1994) resulted in cessation of lay within three weeks. Upon return to a balanced sodium diet, 
egg production increased to control levels (Nesbeth et al., 1976a). Using a low sodium diet 42 days as an alternative to induce molt did result in increased egg weight and egg specific gravity above that of the control; however, feeding a low sodium diet led to a $59 \%$ decrease in feed intake that resulted in a 19\% loss in hen body weight (Nesbeth et al., 1976b). Feeding a diet containing 150 times the daily recommended zinc content (NRC, 1994; in the form of zinc acetate or zinc oxide), eliminated production within one week and decreased feed intake by at least 50\% depending on the dietary zinc concentration (Shippee et al., 1979; Berry and Brake, 1987). There were no improvements in egg specific gravity, internal egg quality, or egg production for hens induced to molt by a high zinc diet compared to traditional feed withdrawal (Shippee et al., 1979).

Wheat middlings are a low energy and low protein feedstuff. Diets containing a substantial quantity of wheat middlings do not supply the nutrients needed by hens for egg production, but provide bulk feedstuff to increase gut fill. A diet containing approximately 94\% wheat middlings reduced (i.e., 8\% of production) or eliminated egg production within eight to 28 days (Biggs et al., 2003; Biggs et al., 2004). The wheat middling containing diet resulted in an immediate decrease in lay, but did not result in increased egg production, improved internal egg quality (i.e., albumen height or egg weight) or egg specific gravity compared to those molted by feed withdrawal (Biggs et al., 2003; Biggs et al., 2004). Hens consuming a wheat middling diet lost on average $13 \%$ of their initial body weight during treatment, which was due to a $30 \%$ reduction in feed intake (Biggs et al., 2003; Biggs et al., 2004). 
The large yellow follicles found on the ovary are supported by two gonadotropins, LH and FSH. These two gonadotropins are secreted from the anterior pituitary in response to $\mathrm{GnRH}$ released from the hypothalamus. The $\mathrm{GnRH}$ release is regulated in a negative feedback loop by the steroids progesterone and estrogen. Disruption of this hypothalamic-hypophyseal- gonadal axis results in interruption of egg production. It has been speculated that regression of the reproductive tract, which occurs during a molt, and the post-molt rejuvenation are both essential for the observed increase in post-molt performance (Brake and Thraxton, 1979). Alternative methods that can effectively alter the hypothalamic-hypophyseal-gonadal axis, causing reversible regression of the reproductive tract without extreme hen weight loss or other physiological insult to the hen, would be preferred compared to feed withdrawal or nutrient restriction to induce a molt. In the current experiment daily oral administration of 4 or $8 \mathrm{mg}$ of MGA per day resulted in a decline in egg production (Figure 1) subsequent to regression of the large yellow follicles (Figure 2) and the oviduct (Figure 3, 4, 5 and 6). These results are similar to other studies in which the hypothalamic-hypophyseal-gonadal axis was altered by some antigonadotrophic hormone. Constant infusion of a GnRH agonist (which desensitizes the pituitary to $\mathrm{GnRH}$ ) has been shown to cause a reduction in progesterone concentration and the weight of the ovary and oviduct leading to cessation of lay (Dickerman and Bahr, 1989). Injecting LH, FSH, LH with progesterone or FSH with progesterone has been shown to interrupt or eliminate lay for at least three weeks (Juhn et al., 1956). Enheptin, an antigonadotropin, suppressed the onset of lay (Pino and Hudson, 1953). Similar results were found when feeding or injecting progesterone, also an antigonadotropin (Adams, 1956; Shaffner, 1954; Gabuten and Shaffner, 1954). 
Interference with the hypothalamic-hypophyseal-gonadal axis by any means can result in a loss of gonadotropic support of the large yellow follicles resulting in a loss of steroidogenic support for the oviduct.

The physiological responses that occur during traditional molting (i.e. hen weight loss, feather molt and complete cessation of lay) are used as indicators of molt effectiveness and considered important to increase post-molt performance. However, the key to increasing egg quality post-molt is regression and rejuvenation of the cells that line the reproductive tract (Brake and Thaxton, 1979). Traditional feed withdrawal induced molting and current alternative methods of inducing molt interfere with the hypothalamic-hypophyseal-gonadal axis by nutrient deprivation, whereas the method used in the current experiment uses a well understood physiological mechanism to effectively shut down the hypothalamic-hypophyseal-gonadal axis leading to regression and rejuvenation of the reproductive tract.

\section{Implications}

Inducing a molt with MGA adequately addresses hen well-being because hens are maintained on a balanced layer diet. It can be easily administered to a hen population because it is administered through the feed and does not require handling the birds. The entire process of molting is shorter when molting with MGA than with traditional molting, which is important when looking at the time out of production. While there is an additional cost that is applied with comparing feed withdrawal to an alternative in which hens are fed throughout the process there many other benefits, including a method that address hen well-being concerns. 


\section{Literature Cited}

Adams, J. L. 1955. Progesterone-induced unseasonable molt in single comb white leghorn pullets. Poult. Sci. 34:702-707.

Adams, J. L. 1956. A comparison of different methods of progesterone administration to the fowl in affecting egg production and molt. Poult. Sci. 35:323-326.

Berry, W. D. 2003. The physiology of induced molting. Poult. Sci. 82:971-980

Berry, W. D., J. Brake. 1987. Postmolt performance of laying hens molted by high dietary zinc, low dietary sodium, and fasting: egg production and eggshell quality. Poult. Sci. 66:218-226.

Biggs, P. E., M. E. Persia, K.W. Koelkebeck, C.M. Parsons. 2004. Further evaluation of nonfeed removal methods for molting programs. Poult. Sci. 83:745-752.

Biggs, P. E., M.W. Douglas, K. W. Koelkebeck, C. M. Parsons. 2003. Evaluation of nonfeed removal methods for molting programs. Poult. Sci. 82:749-753.

Brake, J., P. Thraxton. 1979. Physiological changes in caged layers during a forced molt. Gross changes in organs. Poult. Sci. 58:707-716.

Dickerman, R. W., J. M. Bahr. 1989. Molting induced by gonadotropin-releasing hormone agonist as a model for studying endocrine mechanisms of molting in laying hens. Poult. Sci. 68:1402-1408

Douglas, C. R., R. H. Harms, H. R. Wilson. 1972. The use of extremely low dietary calcium to alter the production pattern of laying hens. Poult. Sci. 51:2015-2020.

Gabuten, A. R., C. S. Shaffner. 1954. A study of the physiological mechanisms affecting specific gravity of chicken eggs. Poult. Sci. 34:47-53. 
Gast, R. K., S. C. Ricket. 2003. Symposium: current and future prospects for induced molting in laying hens. Poult. Sic. 82:964.

Juhn M., P. C. Harris. 1956. Responses in molt and lay of fowl to progestins and gondaotrophins. Proc. Soc. Exp. Biol. Med. 92:709-711.

Lumijarvi, D. H., T. I. Koike, F. W. Hill. 1966 Effects of Na deficiency in the chick on water intake and fluid volumes, plasma organ weight changes. Poult. Sci. 45:1101101.

National Research Council. 1994. Nutrient Recuirements of Poultry. 9th rev. ed. National Academy Press. Washington, DC.

Nevalainen, T. J. 1969. The effect of calcium-deficient diet on the reproductive organs of the hen. Poult. Sci. 48:653-659.

Nesbeth, W. G., C. R. Douglas, R. H. Harms. 1976a. The potential use of dietary salt deficiency for the force resting of laying hens. Poult. Sci. 55:2375-2379.

Nesbeth, W. G., C. R. Douglas, R. H. Harms. 1976b. response of laying hens to low salt diet. Poult. Sci. 55:2128-2133.

Pino, J. A., C. B. Hudson. 1953. Duration of sexual retardation in S.C. white leghorn pullets and cockerels following enheptin (2-amino, 5-nitrothiazole) feeding. Poult. Sci. 32:650-655.

Seigle, H. S., 1961. Effect of level of dietary salt on the histology of the adrenal and kidney of young chickens. Poult. Sci. 40:1455-1456.

Shaffner, C. S. 1954. Feather papilla stimulation by progesterone. Science. 120:345.

Shaffner, C. S. 1955. Progesterone induced molt. Poult. Sci. 34:840-842. 
Shippee, R. L., P. E. Stake, U. Koehn, J. L. Lambert, R. W. Simmons III. 1979. High dietary zinc or magnesium as forced-resting agents for laying hens. Poult. Sci. 58:949-954. 
Melengestrol acetate as an alternative method to induce molting and the effect on post-

\author{
molt egg quality ${ }^{1,2}$ \\ J.M. Koch ${ }^{3}$ J.S. Moritz ${ }^{3}$, D.C. Lay Jr ${ }^{4}$. and M.E. Wilson ${ }^{3,5}$ \\ ${ }^{3}$ Division of Animal and Veterinary Science, Davis College of Agriculture, Forestry and \\ Consumer Science, West Virginia University Morgantown, West Virginia \\ ${ }^{4}$ USDA-ARS Livestock Behavior Research Unit, Purdue University, West Lafayette, \\ Indiana
}

${ }^{1}$ This work is published with the approval of the Director of West Virginia Agriculture and Forestry Experiment Station as scientific paper. This project was supported by a USDA-ARS Specific Cooperative Agreement Agr \# 58-3602-1-172 and Hatch project 321 (NE 161). Disclaimer: The mention of trade names or commercial products in this article is solely for the purpose of providing specific information and does not imply recommendation or endorsement by the U.S. Department of Agriculture.

${ }^{2}$ The authors would like to thank George Siedel for assistance with the statistical analysis ${ }^{5}$ Correspondence: G048 Agricultural Sciences Building (phone: (304) 293-2406 ext. 4425; fax: (304) 293-2232; email: mwilso25@wvu.edu). 


\begin{abstract}
Inducing hens to molt increases egg quality, egg production and extends the productive life of the hens. Molting is normally accomplished by feed withdrawal, which has received criticism, and alternatives described thus far have resulted in poor post-molt performance. Previous studies have shown that MGA at a dosage of 4 or $8 \mathrm{mg}$ per day, when incorporated into a balanced layer diet, leads to reversible regression of the reproductive tract. However, this alternative must also result in an increase in egg quality post-molt to be considered an adequate method by the industry. Hy-Line W-36 (n=72) laying hens at 67 weeks of age were randomly assigned to receive either a diet containing $0 \mathrm{mg}$ MGA (control) throughout the experiment, or 4 or 8 mg MGA per day for 2, 4 or 6 weeks. Eggs were collected daily to determine percent lay throughout the experiment. Upon reaching 50 and 70 percent lay, following removal of MGA, eggs were collected for four days and measurements of egg quality, including haugh units (i.e., internal egg quality), as well as shell thickness and breaking strength (i.e., measures of external egg quality) were determined. Internal egg quality measured by haugh units was greater $(\mathrm{P}<$ 0.05) for those eggs laid by hens molted with a diet containing $8 \mathrm{mg}$ of MGA for four or six weeks compared to controls (81.2 \pm 0.7 vs. $78.4 \pm 0.5)$. Following MGA induced molt, shell thickness was greater $(\mathrm{P}<0.05)$ when hens were treated with $4 \mathrm{mg}$ for six weeks and $8 \mathrm{mg}$ MGA for four and six weeks compared to control $(0.341 \pm 0.004,0.334$ $\pm 0.005,0.358 \pm 0.004$ vs. $0.320 \pm 0.002 \mathrm{~mm})$. Egg breaking strength was greater $(\mathrm{P}<$ 0.05) than controls for all hens fed MGA regardless of dosage or duration of feeding
\end{abstract}


(4.48 \pm 0.06 vs. $3.88 \pm 0.04 \mathrm{~kg})$. To address the food safety concerns about the amount of MGA remaining in the egg, a subset of hens was fed $8 \mathrm{mg}$ of MGA per hen per day for two weeks and eggs were collected for three weeks starting with the last egg laid while the hens were on treatment. Following the return to lay MGA was below the accurate level of detection by the seventh day after removal of MGA from the diet. At all time points the concentration of MGA was three orders of magnitude below the FDA tolerance for MGA in edible tissue which is at .1 parts per billion. When utilized as an alterative method to induce molt, MGA leads to an increase in both the internal (i.e., haugh units) and external (i.e., shell thickness and breaking strength) egg quality compared to nonmolted hens.

Key Words: Chickens, Molting, Melengestrol Acetate, Well-being 


\section{Introduction}

Traditional feed withdrawal induced molting results in increased production, egg quality and extends the productive life of a hen. However, traditional molting practices do not adequately address hen well-being (Berry, 2003). Currently there are several proposed alternative methods to induce molting, but these alternatives also do not adequately address hen well-being concerns (Berry, 2003). Many of the current alternatives are centered on the idea of altering a hen's daily nutrient intake. Examples of these alternatives include feeding low nutrient density diets (i.e., wheat middlings) and diets with altered macro minerals (i.e., low calcium, low sodium or high zinc diets; Berry, 2003). These alternatives attempt to address hen well-being by maintaining hens on some form of feedstuff during molt. However, these alternatives have been found to increase instances of hen paralysis, kidney and adrenal damage and hen dehydration (Berry, 2003; Douglas et al., 1972; Lumijarvi et al., 1966; Seigle, 1961).

Traditional molting thus far is not only the most consistent and repeatable method, but it creates the greatest improvements in post-molt performance. Current alternative methods are unpredictable and unrepeatable among experiments (Berry, 2003). The increase in post-molt performance that is observed by alternative methods like, low calcium, high zinc and wheat middling diets is not greater than the observed increase in feed withdrawal molting. (Douglas et al., 1972; Nevalainen, 1969; Shippee et al., 1979; Biggs et al., 2003; Biggs et al., 2004).

Traditional molting practices result in a rapid decrease in egg production and cessation of lay within one week, but total time spent molting (i.e., cessation of lay, through peak production) is approximately nine weeks which means that hens are at a 
limited production level for a rather lengthy time period. It is speculated that if hens can be maintained on a balanced diet during molting, then body stores will not be depleted and the recovery period to peak, post-molt production will be shorter. The key component to increase post-molt performance is not an overall reduction in hen body weight; however the important aspect is reversible regression of the reproductive tract, especially the epithelial cells that line the oviduct (Brake and Thraxton, 1979). We have previously demonstrated that feeding 4 or $8 \mathrm{mg}$ of melengestrol acetate (MGA) per hen per day in a balanced layer diet results in reversible regression of the reproductive tract (Koch et al., 2005) and does not result in inadequate hen well-being (Koch et al., 2004). Therefore, the objective of the current experiment was to determine if egg quality is improved following an MGA induced molt and if the time required to increase egg quality is shorter than that required for traditional molt.

\section{Materials and Methods}

Hy-Line $\mathrm{W}-36$ laying hens $(\mathrm{N}=500)$ at 65 weeks of age were used for the experiment. All hens were housed three per cage with $186 \mathrm{~cm}^{2}$ of floor space per bird and exposed to 18 hours of light per day. Birds were fed a corn and soybean meal based diet, balanced to meet NRC requirements (Table 3; NRC 1994) and provided ad libitum access to water for 7 weeks before the start of the experiment. All procedures involving animals were approved by the West Virginia University Animal Care and Use Committee.

Hens were randomly assigned to receive 0,4 or $8 \mathrm{mg}$ of MGA (International Nutrition, Omaha, NE) per day in a balanced diet (Koch et al., 2005). Hens were fed the 
Table 3. Composition of the experimental and control diets.

\begin{tabular}{|c|c|c|}
\hline Component & Experimental Diet & Control Diet \\
\hline $\mathrm{Kcal} / \mathrm{kg}$ & 2882 & 2882 \\
\hline Protein (\%) & 17.41 & 17.41 \\
\hline Corn (\%) & 48.12 & 57.62 \\
\hline Soybean (\%) & 27.00 & 27.00 \\
\hline Limestone & 9.20 & 9.14 \\
\hline Propylene Glycol (\%) & 7.27 & - \\
\hline Fat (soy oil; \%) & 3.16 & 2.79 \\
\hline Corn Gluten Meal & 2.72 & 1.50 \\
\hline Defluorniated Phosphate (\%) & 1.92 & 1.39 \\
\hline $\begin{array}{l}\text { Vitamin and mineral } \\
\operatorname{premix}^{1}(\%)\end{array}$ & 0.25 & 0.25 \\
\hline Sodium chloride (\%) & 0.20 & 0.21 \\
\hline Methionine (\%) & 0.17 & 0.10 \\
\hline \multicolumn{3}{|l|}{ Calculated Composition } \\
\hline $\mathrm{ME}(\mathrm{kcal} / \mathrm{kg})$ & 2882.0 & 2882.0 \\
\hline Crude Protein (\%) & 17.38 & 17.38 \\
\hline Methionine (\%) & 0.45 & 0.45 \\
\hline Lysine (\%) & 0.87 & 0.87 \\
\hline Calcium (\%) & 4.20 & 4.20 \\
\hline Available phosphorus (\%) & 0.46 & 0.46 \\
\hline
\end{tabular}

${ }^{1}$ Supplied per kg of diet: manganese, 0.02\%; zinc, 0.02\%; iron, 0.01\%; copper, 0.0025\%; iodine, 0.0003\%; selenium, 0.00003\%; folic acid, $0.69 \mathrm{mg}$; choline, $386 \mathrm{mg}$; riboflavin, $6.61 \mathrm{mg}$; biotin, $0.03 \mathrm{mg}$; vitamin $\mathrm{B}_{6}, 1.38 \mathrm{mg}$; niacin, $27.56 \mathrm{mg}$; panthothenic acid, $6.61 \mathrm{mg}$; thiamine, $2.20 \mathrm{mg}$; menadione, $0.83 \mathrm{mg}$; vitamin $\mathrm{B}_{12}, 0.01 \mathrm{mg}$; vitamin $\mathrm{E}, 16.53 \mathrm{IU}$; vitamin $\mathrm{D}_{3}$, 2133 ICU; vitamin A, 7716 IU 
assigned diet for two, four or six weeks and then were returned to a balanced layer diet. Eggs were collected prior to the start of feeding MGA and collected following MGA treatment when hen groups reached 50\% and 70\% production for four days. Upon reaching $50 \%$ and $70 \%$ eggs were collected for four days and the eggs from each day separated into two groups. One group of eggs were stored at $4{ }^{\circ} \mathrm{C}$ for no more than 3 weeks until breaking strength could be tested and the other group was tested immediately after collection for albumen height, egg weight and shell thickness.

Internal egg quality was determined by haugh units which includes both albumen height and egg weight (haugh units=100 X log[albumen height +7.57 - (1.7 X egg weight.037)]). The weight (g) of individuals egg was determined (QCBI digital balance; TSS, York, England) and the height (mm) of the albumen was determined (QCH albumen height gauge; TSS, York, England). External egg quality was measured by shell thickness (mm; QCT shell thickness micrometers; TSS, York, England) and breaking strength (g; QC-SPA shell strength analyzer; TSS, York, England). A subset of hens $(n=12)$ that were 80 weeks old were housed individually and fed $8 \mathrm{mg}$ of MGA per day for two weeks and eggs were collected starting with the last egg that was laid while birds were fed MGA containing diet and every day following for three weeks. Eggs laid by hens fed the same ration without incorporation of MGA were used as controls. The eggs that were collected were separated into the albumen and yolk and then homogenized before beings stored at -80 degrees until assayed. Extraction of the yolk was modified from the procedure described by the manufacturer for extraction of MGA from muscle or adipose tissue (RIDASCREEN® R-Biopharm AG, Darmstadt, Germany). One gram of yolk was added to $15 \mathrm{ml}$ of petroleum ether, vortexed and placed in a 40 degrees shaking 
water bath overnight. The phases were separated by freezing the extracted yolk at -20 degrees for 1 hour and then centrifuging for 15 minutes at $2000 \mathrm{x}$ g at -15 degrees. The petroleum ether was then decanted into a new vial and evaporated to dryness in a 60 degrees water bath. The residue was redissolved in $2 \mathrm{ml}$ of methanol and defatted at 80 degrees for 45 minutes. The precipitated fats were pelleted at $2000 \mathrm{x}$ g for 5 minutes at -15 degrees. The supernatant was decanted and distilled $\mathrm{H}_{2} \mathrm{O}$ was added to a final ratio of 40:60 (methanol: $\mathrm{dH}_{2} \mathrm{O}$ ). The MGA content in the resultant extract was determined utilizing a commercially available enzyme immunoassay (RIDASCREEN® R-Biopharm AG, Darmstadt, Germany; Lot No. 03303) according to the manufacturers instructions. Extraction efficiency, as determined by the recovery of MGA added to control yolk, was $62.3 \%$, which was similar to that indicated by the manufacturer for bovine perirenal fat (approximately 65\%). The assay cross-reactivity with progesterone is less than $0.003 \%$. The concentration of progesterone was determined on the same samples, using radioimmunoassay (Sheffel et al., 1982) Statistical Analysis

Data for haugh units, shell thickness and breaking strength were analyzed using the GLM procedure of SAS (SAS Inst., Cary, North Carolina). Means were separated using Duncan's multiple comparison test. Data were not different for eggs collected at $50 \%$ and $70 \%$, so data were pooled. The model included the amount of MGA and the duration of feeding. P-values less than 0.05 were considered significant. 


\section{Results}

There was no effect of the duration of MGA feeding on internal egg quality so the data are pooled within an MGA treatment. Post-molt internal egg quality (i.e., Haugh units) was the greatest when hens received $8 \mathrm{mg}$ of MGA per day regardless of the duration of feeding (81.06 $\pm 2.18 \%$ ). Haugh units in the group receiving $4 \mathrm{mg}$ of MGA per hen per day for all durations was not greater than controls (Figure 7).

Shell thickness increased as the duration of MGA feeding increased in both the 4 and $8 \mathrm{mg}$ MGA groups. Shell thickness was greater when four mg of MGA was fed for six weeks than the shell thickness of the control group (Figure 8). Shell thickness was greater in the groups receiving $8 \mathrm{mg}$ of MGA for four or six than those receiving $0 \mathrm{mg}$ of MGA (Figure 8).

Breaking strength was greater in both the 4 and 8 mg MGA groups for all durations of feeding compared to those receiving $0 \mathrm{mg}$ of MGA. Those receiving $4 \mathrm{mg}$ of MGA for four or six weeks had a greater breaking strength than those receiving $4 \mathrm{mg}$ for two weeks (Figure 9). However, the breaking strength observed in the those groups receiving $4 \mathrm{mg}$ of MGA for four or six weeks was similar to the breaking strength of the groups receiving $8 \mathrm{mg}$ of MGA for two, four or six weeks (Figure 9).

The average time required for those groups receiving either 4 or $8 \mathrm{mg}$ of MGA per hen per day, to reach 50\% production after MGA removal was 11 days with the greatest time being 20 days which occurred in those hens receiving $4 \mathrm{mg}$ of MGA for six weeks (Figure 10). The average amount of time it took for egg production to reach $70 \%$ post MGA treatment was 21 days with the longest amount of time being 36 days which also occurred in those groups receiving MGA for six weeks (Figure 11). 


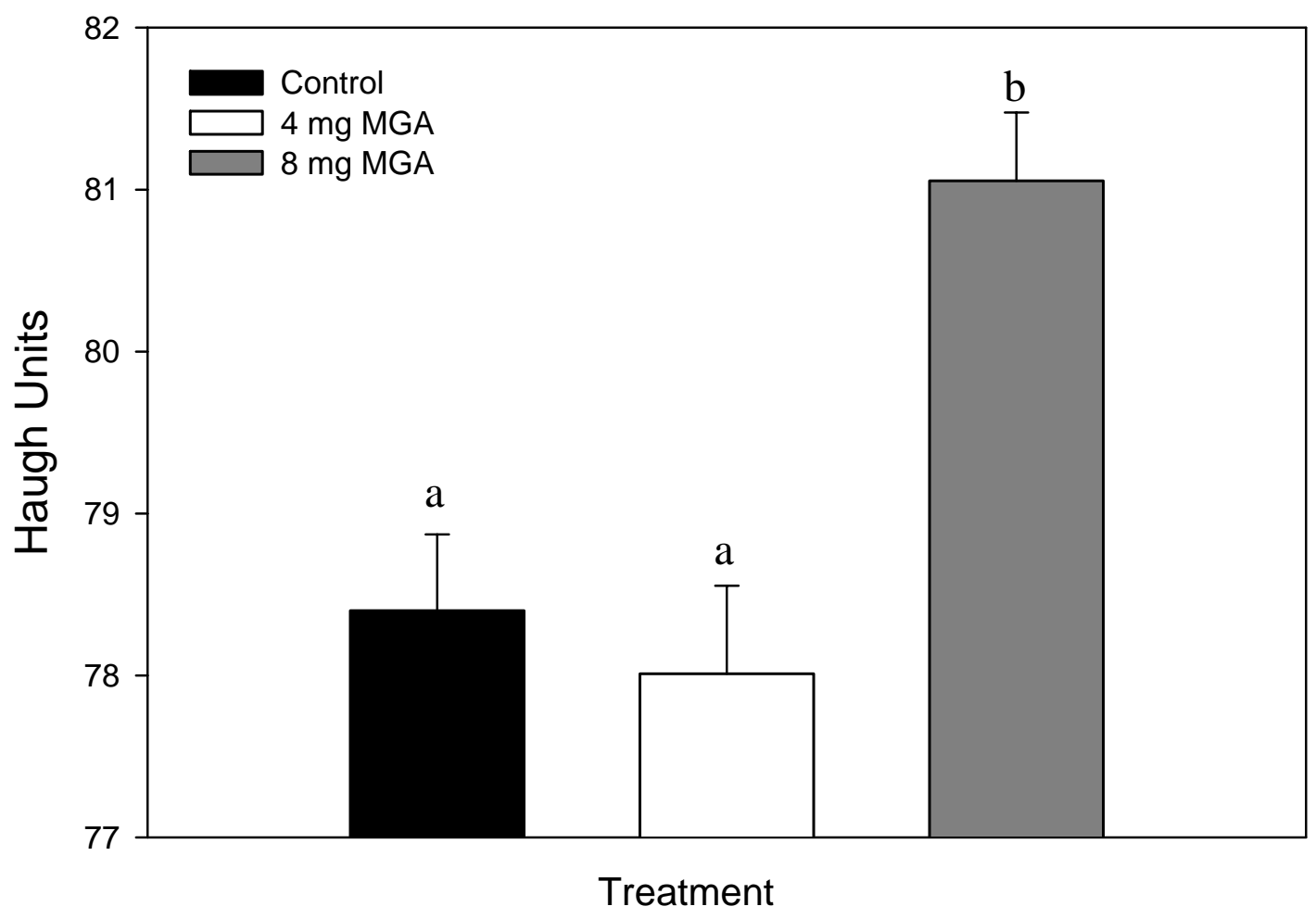

Figure 7. Internal egg quality as measured by haugh units (\%) for eggs laid by hens fed 0,4 or $8 \mathrm{mg}$ of MGA per hen per day, regardless of the duration of MGA feeding. Means \pm SEM with different superscripts different $(\mathrm{P}<0.05)$. 


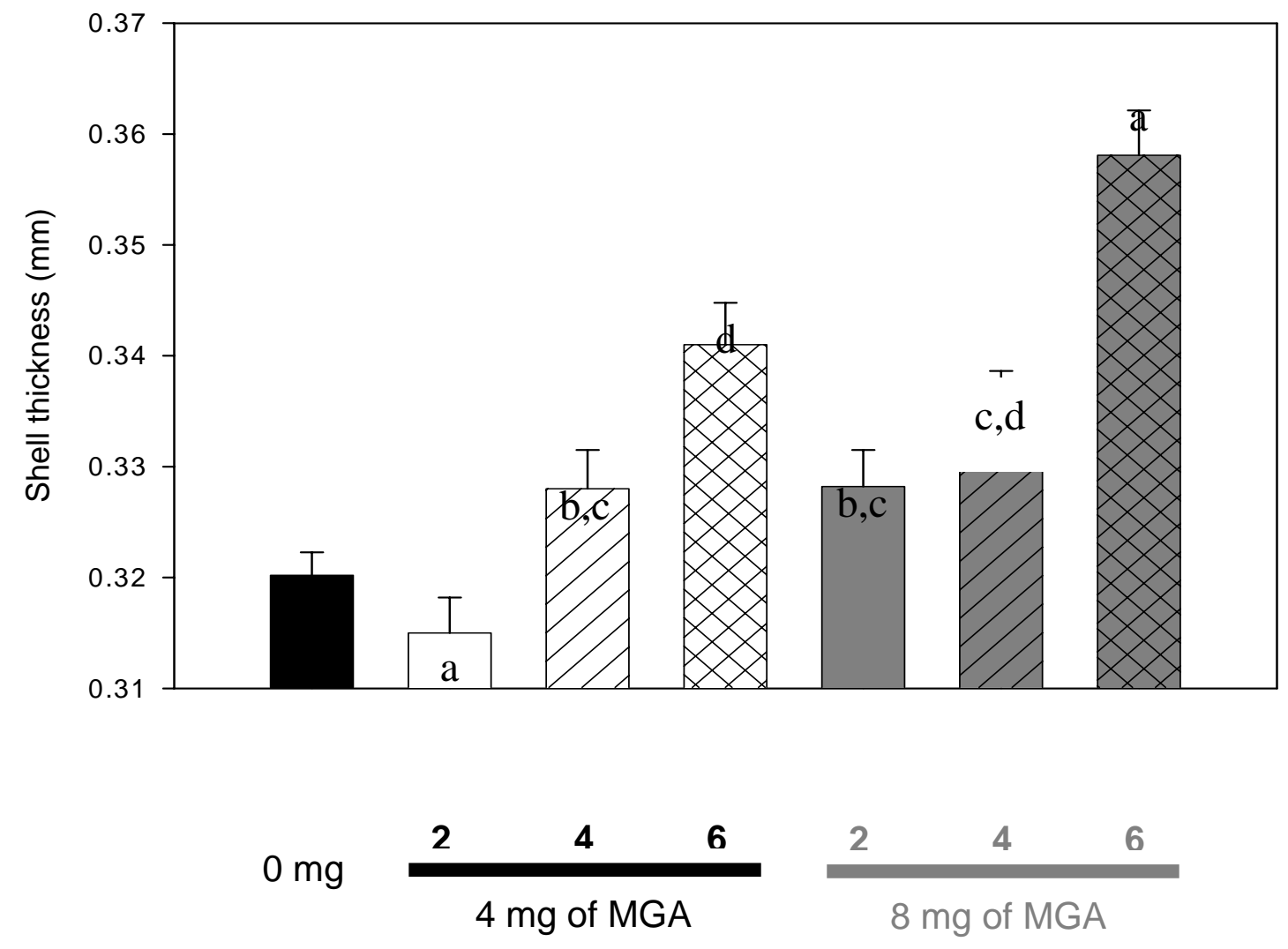

\section{Treatment}

Figure 8. External egg quality as measured by shell thickness ( $\mathrm{mm}$ ) for eggs laid by hens fed either $0 \mathrm{mg}$ of MGA throughout or 4 or $8 \mathrm{mg}$ of MGA per hen per day for 2, 4 or 6 weeks. Means \pm SEM with different superscripts are different $(\mathrm{P}<0.05)$. 


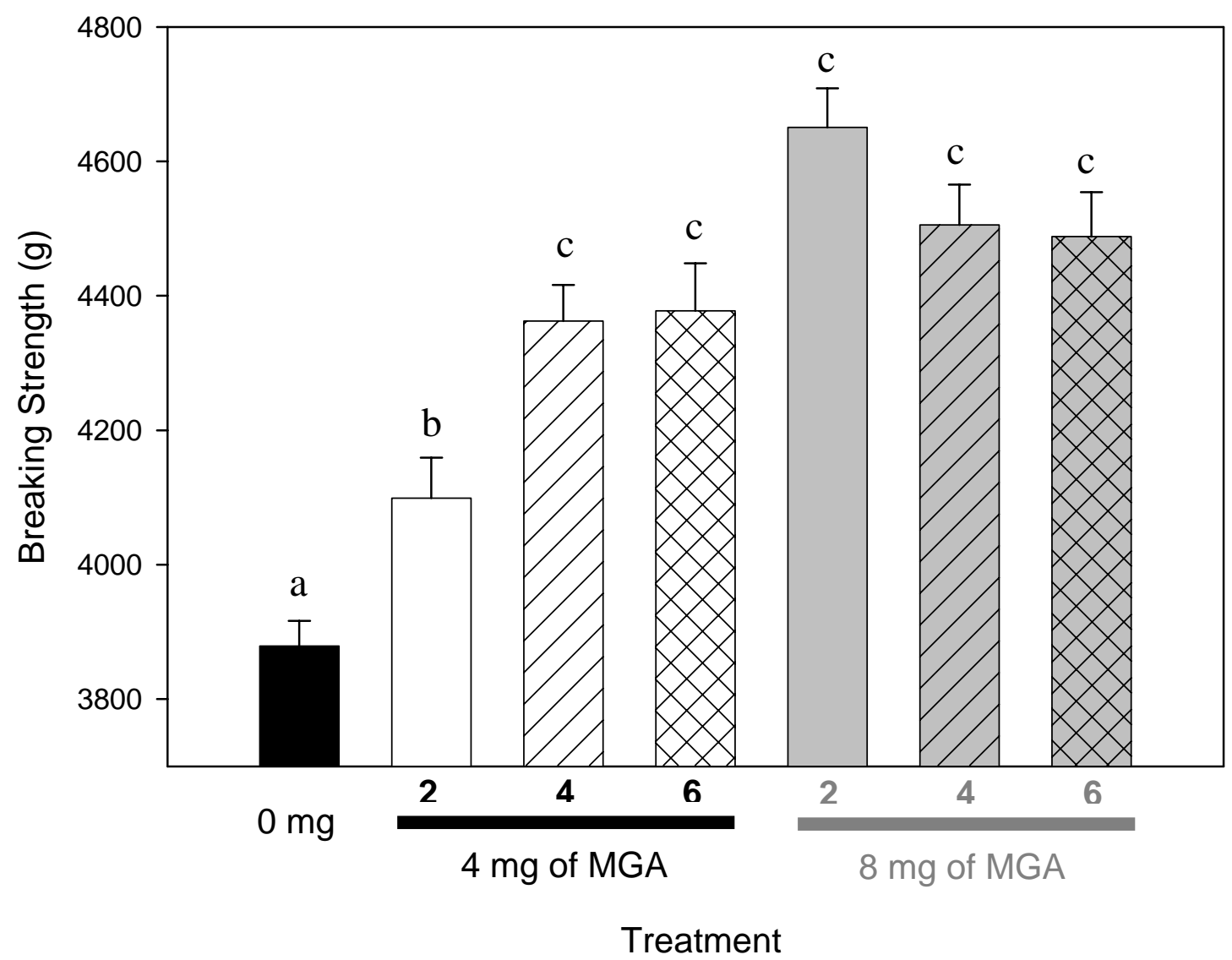

Figure 9. External egg quality as measured by breaking strength (g) for eggs laid by hens fed either $0 \mathrm{mg}$ of MGA throughout or 4 or $8 \mathrm{mg}$ of MGA per hen per day for 2, 4 or 6 weeks. Means \pm SEM with different superscripts different $(\mathrm{P}<0.05)$. 


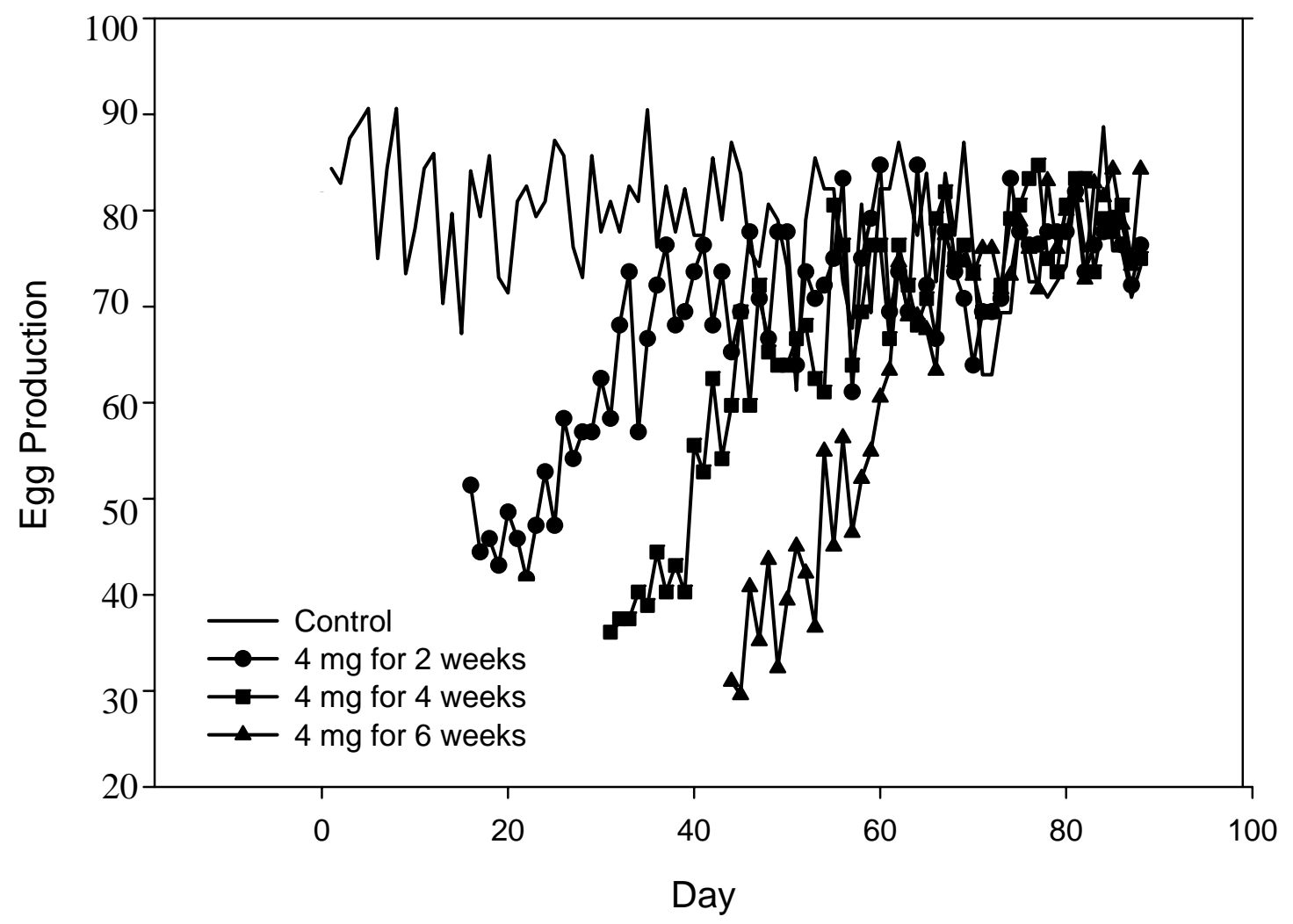

Figure 10. The return to lay after hens were fed $4 \mathrm{mg}$ of MGA per hen per day for either two (circles), four (squares) or six (triangles) weeks. 


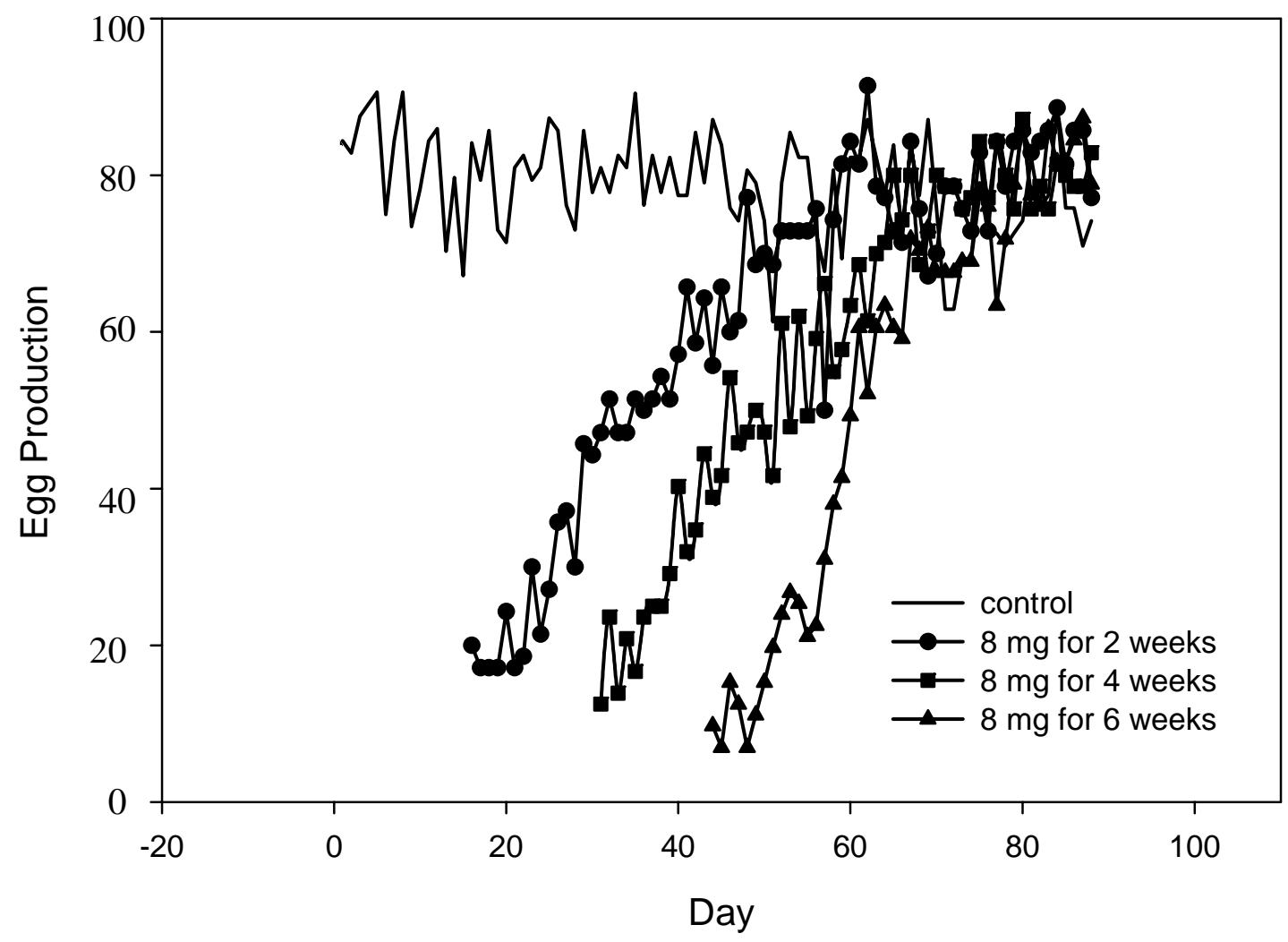

Figure 11. The return to lay after hens were fed $8 \mathrm{mg}$ of MGA per hen per day for either two (circles), four (squares) or six (triangles) weeks. 
The concentration of MGA found in the yolk after MGA removal was approximately 0.3 ppb (Figure 12). The concentration dramatically decreased until the concentration of MGA was below the level of accurate detection by the assay $(0.10 \mathrm{ppb})$ at day seven (Figure 12). MGA was not found at any concentration in the albumen (data not shown). Graphing the concentration of MGA relative to the FDA tolerance level for MGA in edible tissue $(0.025 \mathrm{ng} / \mathrm{ml})$ and the endogenous progesterone concentration (approximately $100 \mathrm{ng} / \mathrm{ml}$ ) demonstrates that yolk MGA concentration is three orders of magnitude below the FDA tolerance level and six orders of magnitude below the endogenous progesterone concentration (Figure 13).

\section{Discussion}

Inducing hens to molt by incorporating MGA into a balanced layer diet at a level of 4 or $8 \mathrm{mg}$ per hen per day resulted in an improvement in egg quality. Breaking strength, a measure of external egg quality, was improved with all MGA amounts and durations with the greatest improvement observed in the eggs laid by hens that had been receiving $8 \mathrm{mg}$ of MGA for either two, four or six weeks. This improvement was similar to the improvement observed in those eggs laid by hens receiving 4 mg of MGA but only for four or six weeks. There was an improvement in breaking strength of those receiving $4 \mathrm{mg}$ of MGA for 2 weeks but this improvement was not as great as the $4 \mathrm{mg}$ of MGA for 4 or six weeks or the $8 \mathrm{mg}$ treatment for two, four or six weeks. Shell thickness, another measure of external egg quality increased as the duration of MGA feeding increased in both treatment groups. The greatest improvement in egg quality was observed in the hens receiving 4 or $8 \mathrm{mg}$ of MGA for six weeks. MGA at a level of $8 \mathrm{mg}$ per hen per day 


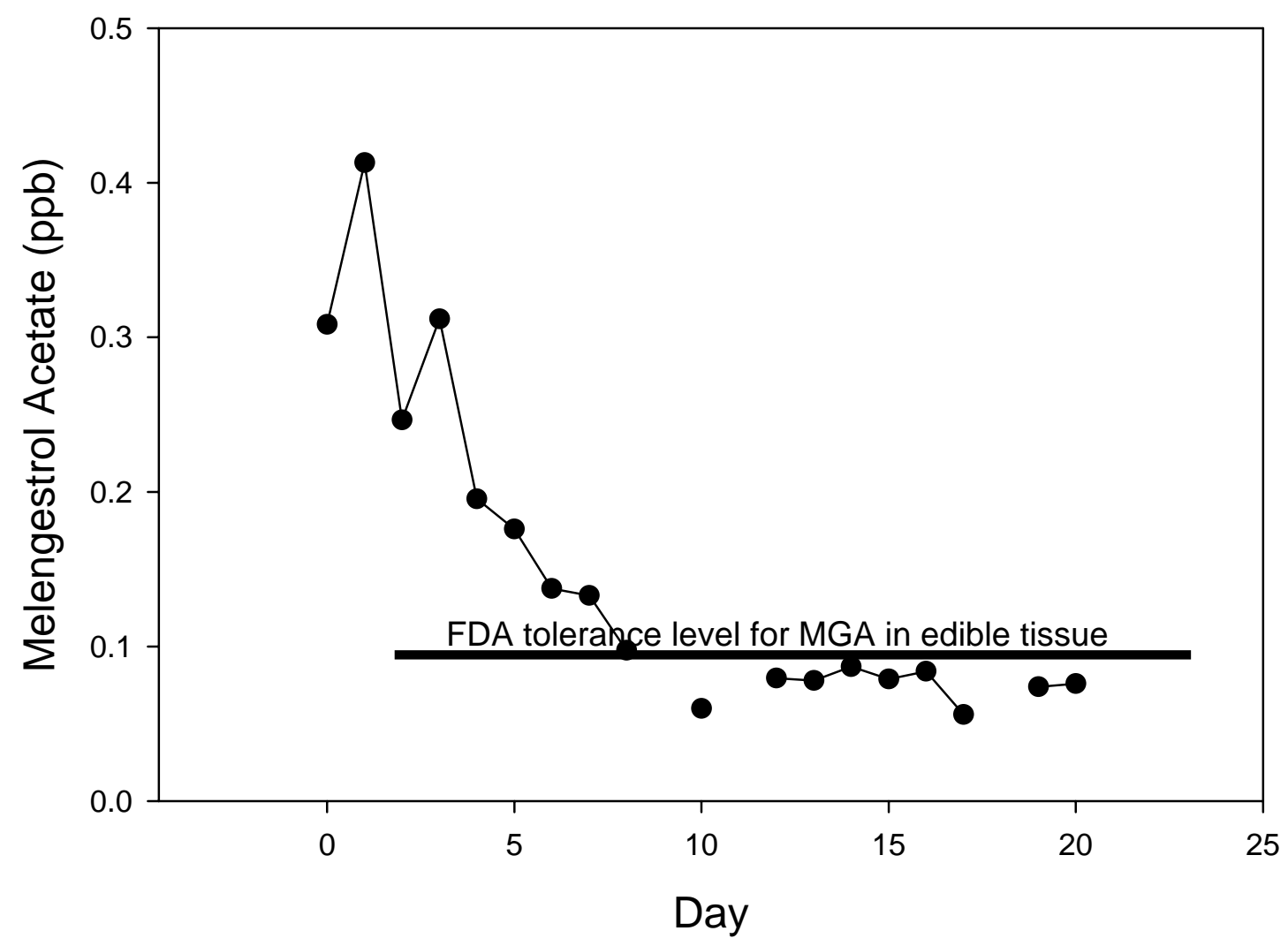

Figure 12. Yolk MGA concentration (ppb) in the days following MGA removal from the diet. Day 0 eggs are representative of the last egg laid while hens were on the last day of a 14 day MGA treatment. 


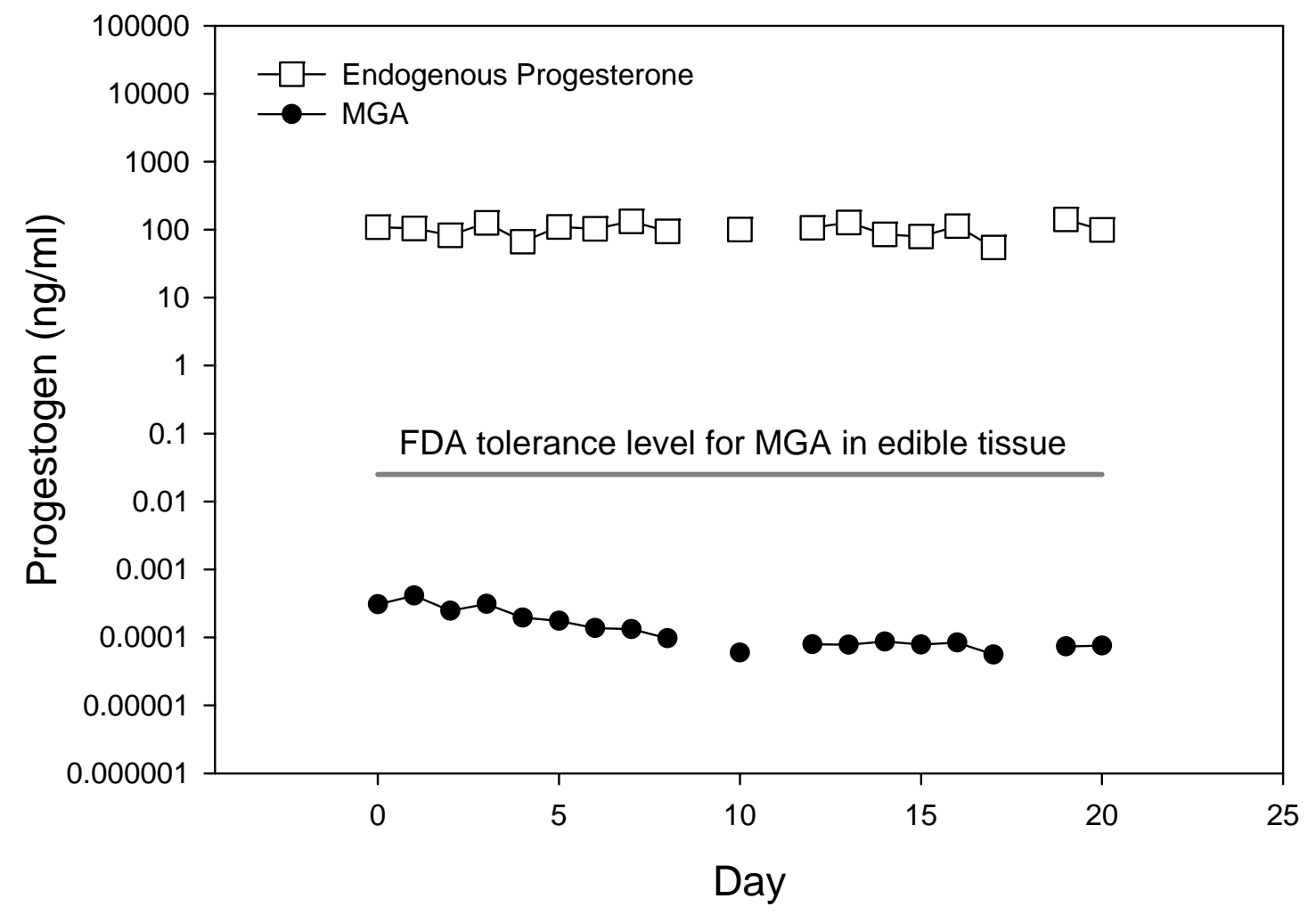

Figure 13. Yolk MGA and endogenous progesterone concentration in the days following removal of MGA from the diet, graphed relative to the FDA tolerance for MGA in edible tissue. Day 0 eggs are representative of the last egg laid while hens were on the last day of a 14 day MGA treatment. The concentration of yolk MGA for those eggs collected on day 0 is three orders of magnitude below the FDA tolerance level and six orders of magnitude below the endogenous progesterone concentration. 
at all durations resulted in the greatest internal egg quality (i.e., as measured by haugh units). It has been previously determined that hens can be induced to molt by the administration of hormones (Adams, 1955; Adams, 1956; Shaffner, 1954, Gabuten and Shaffner, 1954; Dickermann and Bahr, 1979), but the number of experiments that have assessed post-molt egg quality are limited. However, the key to increasing post-molt performance is inducing a molt that leads to reversible regression of the reproductive tract (Brake, 1993). The alternative method that is the most successful at causing reversible regression that results in an increased post-molt performance and addresses hen well-being will be the most desired alternative method.

Current alternative methods to a feed-withdrawal induced molt, are all associated with altering the daily nutrients needed to maintain egg production and required for daily hen maintenance. These alternatives include dietary mineral alterations like low calcium, low sodium or high zinc diets (Douglas et al., 1972; Nevalainen, 1969; Shippee et al., 1979). Another main alternative that has recently been looked into is feeding low nutrient density diets, such as wheat middling (Biggs et al., 2003; Biggs et al., 2002). However, all the these alternatives are potentially use less in the industry because they either lack the ability to increase post-molt performance and/or do not adequately address hen well-being concerns. If an alternative method is going to replace feed withdrawal then it must be result in a better post-molt performance and adequately address hen wellbeing concerns that are not addressed by traditional feed withdrawal. Without meeting these criteria an alternative will not be implemented because it is not cost effective for producers. 
Calcium is important for several components of egg production. Calcium is needed for the GnRH stimulation of the LH surge and is required for LH stimulated progesterone production (Brake, 1993). Besides playing a role in reproductive calcium functions as a major component in hard shell formation. Low calcium diets (i.e. approximately 5\% less calcium than recommended; NRC, 1994) eliminated egg production within 28 days (Douglas et al., 1972). The time required to reach a maximum post-molt production varies between experiments as well as the maximum production reached. Four weeks after being returned to a calcium balanced diet, production had returned to that of non-molted controls (i.e., approximately 55\%; Douglas et al., 1972), in another situation egg production was at $20 \%$ three weeks after being fed a proper calcium diet (Nevalainen, 1969). Feeding a low calcium diet was consistent in that egg quality including: egg specific gravity, shell thickness and shell weight was not improved over the levels before molt (Douglas et al., 1972; Nevalainen, 1969).

Sodium is an important mineral needed to maintain the water balance of the body and it is necessary to supplement a corn and soybean based layer diet with sodium. Feeding and a corn and soybean based diet with no supplemental sodium for 23 days (i.e., containing only $20 \%$ of the recommended sodium concentration; NRC, 1994) leads to induced molting, but there were variable degrees of post-molt performance. Post-molt egg production increased to above the production level of control as well as an increase in egg specific gravity above a non-molted control. However the downside is that it took anywhere from 10 to 21 days to reach peak production post-molt (Nesbeth et al., 1976a; Nesbeth et al., 1976b). Post-molt performance did not follow the same pattern when a low sodium diet was fed for 42 days. Egg production was found to be similar to the 
production rates observed in hens molted by feed withdrawal, but egg specific gravity and egg weight were greater following a 42 day, low sodium molt than that observed following feed withdrawal (Nesbeth et al., 1976b). In another experiment feeding low sodium for 42 days did not result in an observed increase in egg specific gravity, egg weight or haugh units (Naber et al., 1984; Berry and Brake, 1987).

Feeding a high zinc diet results in extreme hen weight loss as a result or a dramatic reduction in feed intake. High concentrations of zinc have been found to limit the formation of cyclic adenosine monophosphate (cAMP) associated with the LH receptor which decreases the production of progesterone (Brake, 1993). Feeding a diet containing 150 times the recommended zinc content (NRC, 1994) has been found to be predictable in the time required to induce molting and the length of time to reach a peak post-molt production. However, in some cases molting by a feeding a high zinc diet does not increase haugh units (i.e., egg weight or albumen height), egg specific gravity or shell thickness (Shippee et al., 1979). In other experiments feeding a high zinc diet to induce molt resulted in increased shell thickness and weight (Berry and Brake 1987).

Feeding a diet that contains a high percentage (i.e., 94-94\%) of a low nutrient dense feedstuff such as wheat middling can quickly induce a flock of hens to undergo a molt as seen with high zinc diets and traditional feed withdrawal. Feeding the same concentration of wheat middling results in repeatable and consistent results. Egg production was improved by feeding a high wheat middling diet, but the improvement was not greater than the improvement seen by traditional feed withdrawal. The same is true for internal egg quality or egg specific gravity (Biggs et al., 2004; Biggs et al., 2003). 
When subjecting food source animals, that are intended for human consumption, to steroids or other drug treatments, there is always concern about the level that can be detected in edible tissue and the amount of time after treatment that it can be detected. To address these concerns the concentration of MGA in the eggs was determined. The amount of MGA found in the yolk was well below (i.e., three orders of magnitude) the FDA tolerance level for MGA in edible tissue.

While the egg quality data presented in this paper is compared to a group of hens that were not subjected to feed withdrawal (i.e., represent the before molt egg quality) Further experiments will be needed to determine the differences in egg quality between traditional molting and the current method described in this paper. However, the fact that feeding MGA improves both internal and external egg quality is promising. Another important component to an MGA induced molt is that the time required to reach peak post-molt production is much shorter than traditional feed withdrawal. It is speculated that this is because hens are maintained on a balanced layer diet so the resting phase (i.e., the period after molting when hens are maintained on restricted protein diet to increase body conditioning) is shortened. Further testing is needed to perfect this method and make it more industry friendly by possibly lowering cost. Changing the duration of artificial lighting has been shown to decrease the duration between the molting treatment and production, which has been found to be a key factor increasing egg quality post-molt (Hurwitz et al., 1995). If lighting or some other component can increase the effectiveness of an MGA induced molt then, the amount of MGA or the duration of feeding may be reduced decreasing the cost of the process. 
In conclusion, incorporating MGA into a balanced layer diet induces molting in hens while they are maintained on balanced layer diet. Maintaining hens on a balanced layer diet throughout molting prevents hen weight loss and decreases a hen's motivation to obtain feed (Koch et al., 2005; Koch et al., 2004). Therefore, this method addresses hen well-being concerns that arise during feed withdrawal and other methods associated with nutrient manipulation. Inducing molt by MGA, allows for a quick recovery to peak production and increases internal and external egg quality. 


\section{Literature Cited}

Adams, J. L. 1955. Progesterone-induced unseasonable molt in single comb white leghorn pullets. Poult. Sci. 34:702-707.

Adams, J. L. 1956. A comparison of different methods of progesterone administration to the fowl in affecting egg production and molt. Poult. Sci. 35:323-326.

Berry, W. D. 2003. The physiology of induced molting. Poult. Sci. 82:971-980.

Berry, W. D., J. Brake. 1987. Postmolt performance of laying hens molted by high dietary zinc, low dietary sodium, and fasting egg production and eggshell quality. Poult. Sci. 66:218-226.

Biggs, P. E., M. E. Persia, K.W. Koelkebeck, C.M. Parsons. 2004. Further evaluation of nonfeed removal methods for molting programs. Poult. Sci. 83:745-752.

Biggs, P. E., M. W. Douglas, K. W. Koelkebeck, C. M. Parsons. 2003. Evaluation of nonfeed removal methods for molting programs. Poult. Sci. 82:749-753.

Brake J. 1993. Recent advances in induced molting. Poult. Sci. 72:929-931.

Brake, J., P. Thaxton. 1979. Physiological changes in chaged layers during forced molt. 2. Gross changes in organs. Poult. Sci. 58:707-716.

Dickerman, R. W., J. M. Bahr. 1989. Molt induced by gonadotropin-releasing hormone agonist as a model for studying endocrine mechanisms of molting in laying hens. Poult. Sci. 68:1402-1408.

Douglas, C. R., R. H. Harms, H. R. Wilson. 1972. The use of extremely low dietary calcium to alter the production pattern of laying hens. Poult. Sci. 51:2015-2020.

Gabuten, A. R., C. S. Shaffner. 1954. A study of the physiological mechanisms affecting specific gravity of chicken eggs. Poult. Sci. 34:47-53. 
Hurwitz, S., E. Wax, Y. Nisenbaum, I. Plavnik. 1995. Responses of laying hens to forced molt procedures of variable length with or without light restriction. Poult. Sci. 74:1745-1753.

Koch, J. M., D. C. Lay Jr., J. S. Mortiz, M. E. Wislon. 2005. Melengestrol acetate (MGA) as an alternative metho to induce molting in hens. Journal of Animal Science 82 (Supplement 1):152.

Koch, J. M., D. C. Lay Jr., J. S. Mortiz, M. E. Wislon. 2004. Alternative method to induce molt that addresses hen well-being. Proceedings of 7th International Society for Applied Ethology North American Regional Meeting: 14.

Lumijarvi, D. H., T. I. Koike, F. W. Hill. 1966. Effects of Na deficiency in the chick on water intake and fluid volumes, plasma electrolytes and plasma osmolality. Poult. Sci. 45:1100-1101.

National Research Council. 1994. Nutrient Recuirements of Poultry. 9th rev. ed. National Academy Press. Washington, DC.

Naber, E. C., J. D. Latshaw, G. A. Marsh. 1984. Effectiveness of low sodium diets for recycling of egg production type hens. Poult. Sci. 63:2419-2429.

Nesbeth, W. G., C. R. Douglas, R. H. Harms. 1976a. The potential use of dietary salt deficiency for the force resting of laying hens. Poult. Sci. 55:2375-2379.

Nesbeth, W. G., C. R. Douglas, R. H. Harms. 1976b. response of laying hens to low salt diet. Poult. Sci. 55:2128-2133.

Nevalaine, T. J. 1969. The effect of calcium-deficient diet on the reproductive organs of the hen (Gallus domesticus). Poult. Sci. 48:653-659. 
Seigle, H. S., 1961. Effect of level of dietary salt on the histology of the adrenal and kidney of young chickens. Poult. Sci. 40:1455-1456.

Shaffner, C. S. 1954. Feather papilla stimulation by progesterone. Science. 120:345.

Sheffel, C. E., Pratt, B. R. Ferrel, E. K. Inskeep. 1982. I. Induced corpora lutea in the postpartum beef cow. II. Effects of treatment with progesterone and gonadotrophins. Jour. Anim. Sci. 54:830-836.

Shippee, R. L., P. E. Stake, U. Koehn, J. L. Lambert, R. W. Simmons. 1979. High dietary zinc or magnesium as forced-resting agents for laying hens. Poult. Sci. 58:949954. 
An alternative method to induce molt that addresses hen well-being ${ }^{1,2}$

\author{
J.M. Koch ${ }^{3}$, K.A. McMunn ${ }^{4,}$ D.C. Lay Jr. ${ }^{4}$, J.S. Moritz ${ }^{3}$ and M.E. Wilson ${ }^{3,5}$ \\ ${ }^{3}$ Division of Animal and Veterinary Science, Davis College of Agriculture, Forestry and \\ Consumer Science, West Virginia University Morgantown, West Virginia \\ ${ }^{4}$ USDA-ARS Livestock Behavior Research Unit, Purdue University, West Lafayette, \\ Indiana
}

${ }^{1}$ This work is published with the approval of the Director of West Virginia Agriculture and Forestry Experiment Station as scientific paper. This project was supported by a USDA-ARS Specific Cooperative Agreement Agr \#58-3602-1-172 and Hatch project 321 (NE 161). Disclaimer: The mention of trade names or commercial products in this article is solely for the purpose of providing specific information and does not imply recommendation or endorsement by the U.S. Department of Agriculture.

${ }^{2}$ The authors would like to thank George Siedel for assistance with the statistical analysis ${ }^{5}$ Correspondence: G048 Agricultural Sciences Building (phone: (304) 293-2406 ext. 4425; fax: (304) 293-2232; email: mwilso25@wvu.edu). 


\begin{abstract}
Molting of hens increases egg quality and production, extending the productive life of hens. The current method used to molt hens has received public criticism regarding hen well-being. Traditional molting is done by withdrawing feed and decreasing light, which leads to weight loss and increased mortality. Alternative methods (feeding low nutrient density feeds or diets low in calcium or zinc), have resulted in poor post-molt performance and increased tissue damage in the hen. An alternative method that results in improved post-molt performance, addresses hen well-being and is economical for producers is desired by the poultry industry. Feeding a progestin should increase hypothalamic negative feedback, decreasing support for the ovary and a subsequent loss of steroidogenic support for the oviduct and cessation of lay. We have demonstrated that incorporating melengestrol acetate (MGA), an orally active progestin, in a balanced layer diet induces reversible regression of the reproductive tract. In this experiment hens were fed one of four diets and tested for their motivation to obtain feed during a molting period. Hy-Line $\mathrm{W}$-36 hens $(\mathrm{N}=64)$ were randomly assigned to one of four treatments for nine days. Hens were fed either a balanced layer diet containing 7.27 \% propylene glycol (control), the same diet containing $8 \mathrm{mg}$ of MGA per day in propylene glycol (MGA), 100\% wheat middling diet or received no feed (restricted). Three weeks prior to starting the experiment hens were trained to peck a disk in order to receive a feed reward based on a progressive ratio reinforcement schedule. Hens that were not successfully trained were excluded from the experiment. Motivation of hens to acquire feed was tested for 15 minutes on days $0,3,6$ and 9 . The total number of pecks (pecks) and total number of feed rewards (rewards) per bird were recorded. There was no
\end{abstract}


increase in pecks per treatment $(47.2 \pm 8.6)$ or rewards per treatment(6.8 \pm 0.9$)$ in either control or MGA hens from day 0 to 9 . However, by day 9 there was marked increase (p $<0.05)$ for restricted hens in pecks (33.1 \pm 6.4 vs. $141.5 \pm 56.0)$ and rewards $(6.5 \pm 0.9$

vs. $14.2 \pm 3.5)$. Hens that were fed a high wheat middling diet had a decreased $(\mathrm{P}<0.05)$ number of pecks ( $23.0 \pm 12.4$ vs. $4.9 \pm 1.1)$ and rewards ( $5.0 \pm 1.5$ vs. $2.1 \pm 0.4)$. Hens that are molted by feeding MGA are not more motivated to acquire feed than control hens, and less motivated than hens on a restricted diet. Therefore feeding MGA is an effective method to induce molt that also addresses the well-being of the hen.

Key Words: Chickens, Molting, Melengestrol Acetate, Well-being 


\section{Introduction}

Molting is a technique that can be used by the poultry industry to increase egg quality, egg production and to extend the productive of hen. The traditional method used to induce molting has started receiving public criticism over the last few years because, to induce molt, hens are withheld from feed for 10 to 14 days or until hens lose $33 \%$ of their original body weight. During molting some protocols call for a decrease in lighting and limit water intake. As a result of these conditions traditional molting does not adequately address hen well-being. Consumers opinions have a great impact on industry practices. Recently McDonald’s (purchaser of over 1 billion eggs each year; Gast and Ricket, 2003) has stated that they will no longer purchase eggs that are produced by hens that have undergone feed withdrawal induced molt. In response to public concern the United Egg Producers and individual researchers have started to invest a lot of time and money into finding an alternative method that adequately addresses hen well-being and is practical for producers (i.e., easy to administer and increases post-molt performance).

The current methods to induce molting do not address the two major problems that arise including hen well-being concerns and industry practicality. Potential alternatives are feeding diets with altered nutrient content. These include low nutrient density diets such as a 95\% wheat middling diet, or diets with alternations in their daily nutrient requirements (i.e., low calcium, low sodium or high zinc; Biggs et al., 2004; Douglas et al., 1972; Nesbeth et al., 1976; Berry and Brake, 1987). While these alternatives would appear to address hen well-being concerns by maintaining hens on some type of feedstuff, these alternatives likely do not adequately address hen well-being. These alternatives have been shown to increase the instances of hen paralysis, result in 
kidney and adrenal damage, hen dehydration and extreme body weight loss (Douglas, et al., 1972; Seigle, 1961; Nesbeth et al., 1976; Biggs et al., 2004).

All of these alternatives assume that hen well-being is improved compared to traditional methods because hens are maintained on some feedstuff during molting. However, the hen's state of well-being has not been tested. Testing well-being is difficult because the results obtained can be difficult to interpret. One method that has been used to obtain a hens state of well-being is by testing the hen's motivation to obtain feed (Savory et al., 1993). Using operant conditioning an animal can be trained to perform a specific task in order to receive desired rewards. This method has been extensively used in swine to determine motivation and preferences (Roberts et al., 1997; Hocking et al. 1993; Savory et al., 1993; DeJong et al., 2002). However, the method has been adapted to the poultry industry to test the motivation of broiler breeders to obtain feed during periods of feed restriction (Savory et al., 1993).

The objective of the current study was to determine the motivational state of hens while being fed three molting diets, traditional feed withdrawal, wheat middling and balanced layer diet including MGA.

\section{Materials and Methods}

Hy-Line $\mathrm{W}$-36 laying hens ( $\mathrm{N}=64)$ at 70 weeks of age were housed individually in a cage with $1544 \mathrm{~cm}^{2}$ of floor space and exposed to 18 hours of day light and provided ad libitum access to water and a layer ration until the start of the experiment. All procedures were approved by the West Virginia University Animal Care and Use Committee. 
Prior to the start of the experiment hens were blocked by weight and assigned to one of the four treatments ( $\mathrm{n}=16), 7.27 \%$ propolyene glycol (i.e., the carrier for MGA, 0 mg of MGA) in a balanced layer diet, 8 mg of MGA in a balanced layer diet (Koch et al., 2005), $100 \%$ wheat middling or feed restricted. Four identical rooms were used for the experiment, each equipped with identical ventilation and lighting systems. Each room was used to house one group of hens all on the same treatment to avoid hen interaction during the experiment (particularly between those that were and were not fed). Prior to the start of the treatment, hens were trained to peck a disk in order to gain access to feed. Each hen was trained and tested in one of ten identical testing pens. Each pen was equipped with a disk for activating feed reward (about $5 \mathrm{~mm}$ in diameter, yellow with a red dot in the center) a hole in the front of the cage to access fed. Each fed pan was attached to an arm which was connected to a motor. Upon proper activation of the switch the motor was programmed to rotate 180 degrees stopping in front of the cage for three seconds. This allows hens to receive rewards for three seconds before rotating an additional 180 degrees to the off position. Each disk and arm was connected to a Switch and Sense 8 (Measurement Computing Corp., Middleboro, MA) box that was operated by a personal computer. The apparatus and protocol used in this experiment was similar to those used by Savory et al., 1993.

Twelve hours before testing, feed was removed from the feeders to insure some state of hunger and motivation. On day 0 (prior to initiation of experiment) and on days 3, 6 and 9 each hens' motivation to acquire feed was tested using a progressive ratio reinforcement schedule in that the first peck of the disk resulted in a feed reward and each additional reward required one more peck of the stimulus disk than the previous reward. 
Total number of pecks and the number of feed rewards were recorded. Requiring hens to "work" for their feed provided a quantitative means to assess how hungry they feel. During testing hens were rewarded with their respective treatment diets, to avoid false responses, because hens may be more highly motivated to receive a different feedstuff due to novelty, rather than pecking the disc because they are hungry.

Hens were videotaped for 16 hours per day in their home cages, and the recordings from days 0 (prior to the initiation of the experiment), 4 and 8 were digitized and then analyzed for the total distance moved by the bird, as a measure of activity, utilizing Ethovision (Noldus, Wageningen, Netherlands). Statistical Analysis

Data for total number of pecks total, number of rewards and the total distance moved per half hour were analyzed using the GLM procedure of SAS (SAS Inst., Cary, North Carolina) by treatment. Hens that did not learn to perform the task were not used for the motivation testing portion of the experiment. The model included the day of testing and hens nested within treatment. The effect of day on the response variables were tested using the hens nested within treatment term as the error term. P-values less than 0.05 were considered significant.

\section{Results}

In both control hens and hens fed MGA, there was no increase in either the total number of pecks or the number of feed rewards throughout the experiment; however, there was a marked increase in both the total number of pecks and the number of feed rewards throughout the experiment in the feed withdrawal group (Figure 14 and Figure 15) by day nine. There was a decrease in the total number of pecks and the total number 
of rewards received by the wheat middling group (Figure 14 and Figure 15) by day nine. These data indicate that when hens were deprived of feed they were willing to work for access to additional feed. However, when hens were fed a balanced layer diet or a balanced diet containing MGA they did not work as hard indicating that they were less hungry. Although there was a transient decrease in activity on day 4 for the control birds (Figure 16), their activity had returned to baseline by day 8 . Those fed MGA or wheat middlings did not exhibit any change in activity throughout the experiment; however, the hens that were not fed, had a marked increase in activity by the eighth day of the experiment (Figure 16) indicating that they were performing feed-seeking behavior within the confines of the cage. 


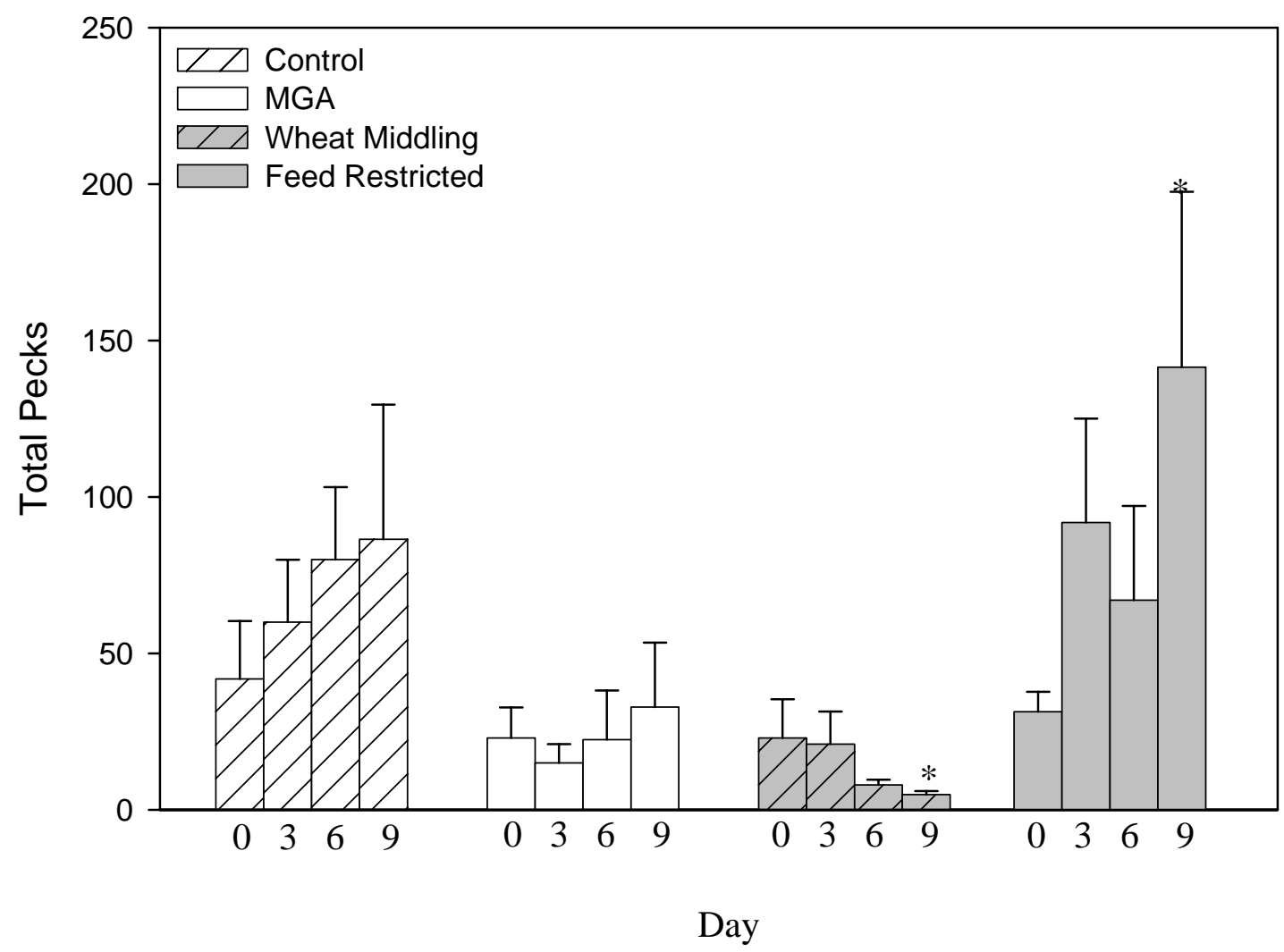

Figure 14. Total number of pecks performed during the motivation test on days $0,3,6$ and 9 for hens fed a control diet, $8 \mathrm{mg}$ per day of MGA, 100\% wheat middling diet, or not fed. There was no change in the total number of pecks performed in either the control or the MGA groups throughout the experiment. However, the restricted hens increases ( $P$ $<0.05$ ) the number of pecks performed by the end of the 9 days. The wheat middling hens decreased $(\mathrm{P}<0.05)$ the number of pecks performed by the end of the 9 days. 


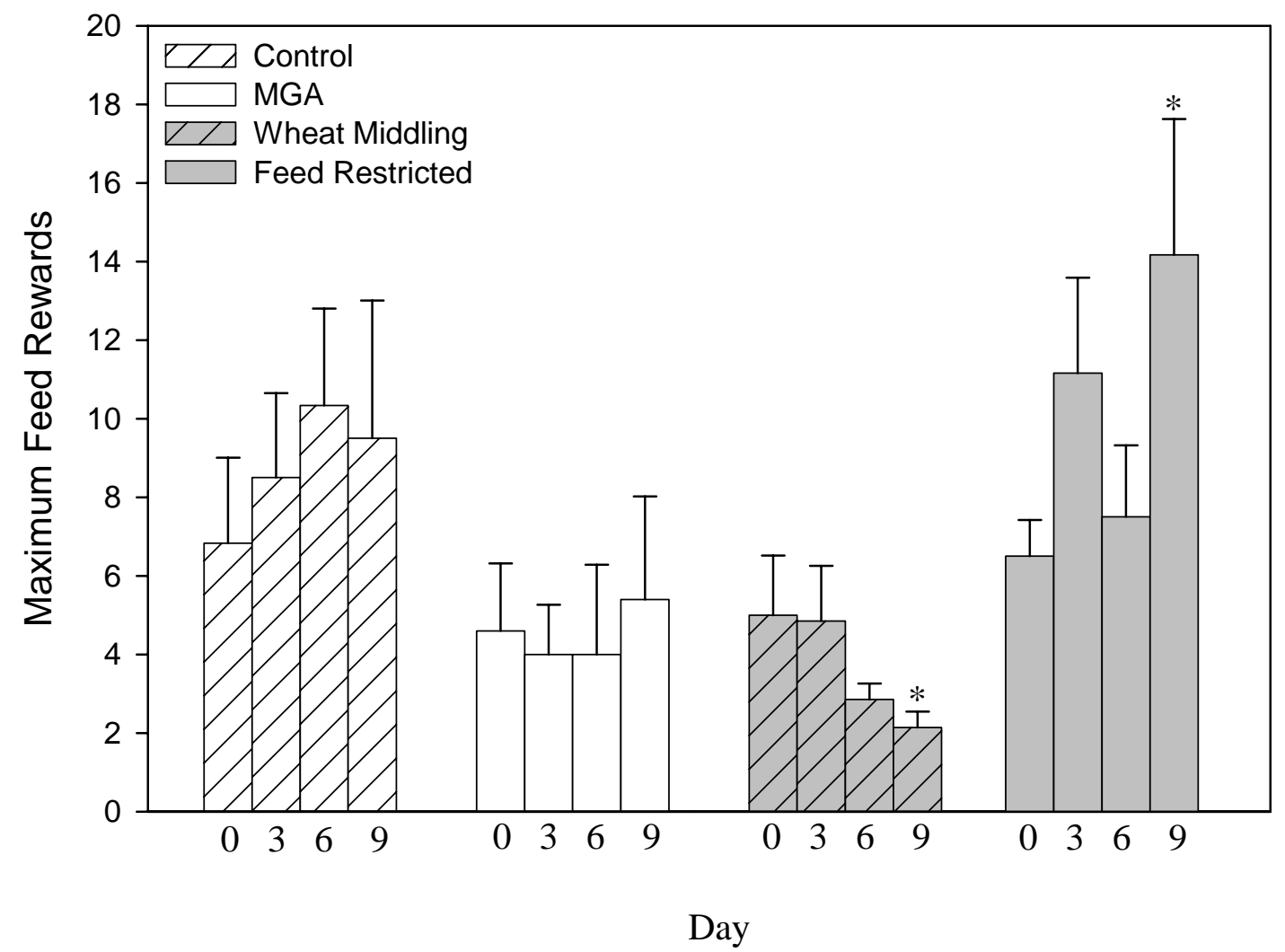

Figure 15. Total number of rewards received during the motivation test on days $0,3,6$ and 9 for hens fed a control diet, $8 \mathrm{mg}$ per day of MGA, 100\% wheat middling diets or not fed. There was not change in the total number of rewards received in either the control or MGA groups throughout the experiment. However, the restricted hens increased $(\mathrm{P}<0.05)$ the number of rewards received by the end of the 9 days. The wheat middling hens decreased $(\mathrm{P}<0.05)$ the number of rewards received by the end of the 9 days. 


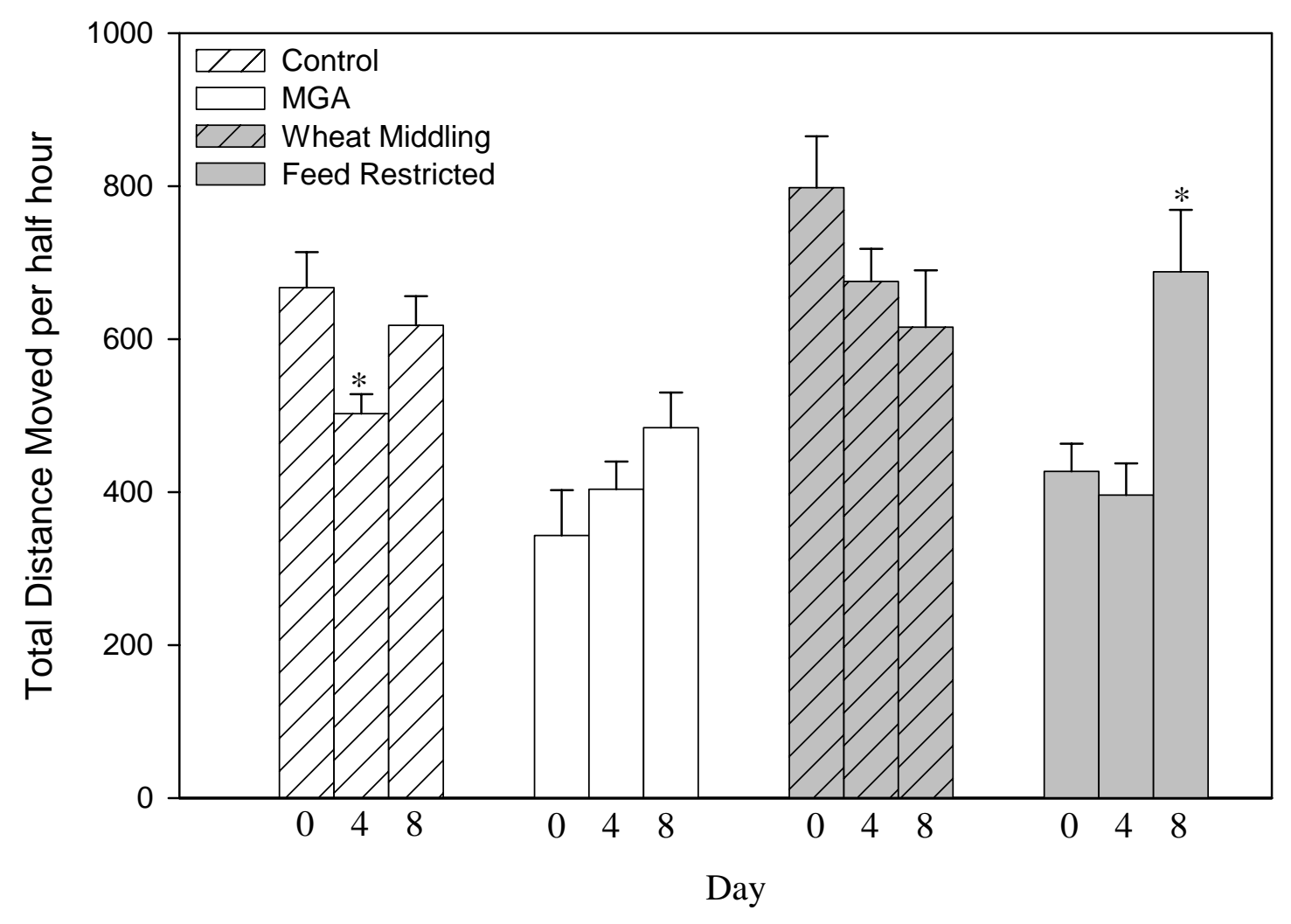

Figure 16. Total distance moved per half hour for hens fed a control diet, 8 mg per day of MGA, $100 \%$ wheat middling diet, or not fed. There was no change in the total distance moved in either the control or MGA groups throughout the experiment. However, in the restricted hens increased $(\mathrm{P}<0.05)$ the total distance moved by the 8 day. 


\section{Discussion}

Molting by incorporation of $8 \mathrm{mg}$ of MGA per hen per day in a balanced layer diet did not increase the motivation of hens to obtain feed during the molting period. In fact the motivation of hens receiving an MGA diet was similar to those receiving a balanced layer diet with no MGA throughout the nine day period. Feeding a $100 \%$ wheat middling diet resulted in a decrease in hen motivation by day nine. However, those hens placed on feed restriction had an increased motivation to work for feed as shown by the increase in total number of pecks and total number of rewards received by day nine. The total distance moved by per half hour was not different throughout the experiment in those groups receiving either the MGA diet or the wheat middling diet. Those that were feed restricted had an increased the total distance moved per half hour by day eight.

Alternatives thus far have result in a dramatic decrease in feed intake, as seen when feeding low sodium (i.e., 59\% decrease; Nesbeth et al., 1976) and high zinc diets (i.e., 20\% decrease; Shippee et al., 1979). Associated with a decrease in feed intake is a decrease in hen body weight. One experiment feeding a low sodium diet resulted hens losing $19 \%$ of their body weight. While feeding a diet containing $94 \%$ wheat middling hen body weight was decreased by 13\% (Nesbeth et al., 1976; Biggs et al., 2003; Biggs et al., 2004). In some experiments altering the nutrient content increased incidence of hen paralysis, increased kidney and adrenal gland damage and hen dehydration (Berry, 2003; Douglas et al., 1972; Lumijarvi et al., 1966; Seigle, 1961). As a result hen well-being can not be determined by only measuring feed intake or body weight loss. To accurate assess hen well-being other methods should also be used in conjunction with feed intake and hen weight loss. 
Several studies have tried to assess animal well-being by determining an animal's motivation to obtain feed (Roberts et al., 1997; Hocking et al. 1993; Savory et al., 1993; De Jong et al., 2002). The motivation of an animal to obtain feed has been used to make an objective decision on their state of well-being and while it is only one measurement it can be combined with other information (i.e., performed stereotypies and amount of activity) to make a better assessment of an animal's state of well-being. Previous research has been done using operant conditioning to test the motivation of broiler breeders, gestating sows and boars to obtain feed while being fed different diet restrictions as implemented by the industries (Van den Brand et al., 2000; Roberts et al., 1997; Hocking et al., 1993).

The feed restriction placed on broiler breeders to limit sexual maturity results in a $65 \%$ lower body weight (i.e., the decrease is related to weight the hens would be if fed ad libitum). Motivation testing has shown that hens placed on a restricted diet are more motivated to work for feed by pecking the operant more times in a 15 minute period. As a result those on feed restriction received more rewards in 15 minutes than the group that was fed an ad libitum diet. It was concluded that the feeding motivation of restricted hens is almost four times greater than ad libitum fed (Savory et al., 1993).

Pregnant sows that are placed on feed restriction have been found to be more motivated to obtain feed then those fed ad libitum. In fact increasing the degree of restriction or increasing the period of restriction leads to increased motivation of the animal to obtain feed. (Lawrence and Illius, 1989; Lawrence et al., 1989). Sows placed on a $60 \%$ feed restriction are considered extremely hungry (i.e., motivated) because many 
will exert more energy to work for the reward than the amount of energy they can get out of the reward (i.e., working at an energy deficit; Huston, 1991).

Diet dilution (i.e., adding oat feed, straw or wheat middling) has been proposed to ameliorate hunger by increasing gut fill in attempts to decrease feeding motivation and thereby addressing hen well-being. Adding bulk (i.e., oat feed) to a broiler breeder diet did not decrease a bird's motivation to obtain feed (Savory and Lariviere, 2000). The same is true for swine, in that adding bulk (i.e., straw) to a nutrient restricted diet did not decrease a pigs motivation to obtain feed (Lawrence et al., 1989; Roberts et al., 1993; Roberts et al., 1997). It was found that increasing the nutrient and energy content of these bulk diet did result in decreased motivation of the pigs to obtain food (Lawrence et al., 1989; Roberts et al., 1993; Roberts et al., 1997). In the current experiment however, there was a decline in motivation to obtain feed in the wheat middling group. This was unexpected, but can be attributed to findings that show a decrease in feed consumption during the first week of being maintained on a $94 \%$ wheat middling diet. In the same experiment it was shown that the weeks following the initial week on a wheat middling diet, feed intake increased two fold. The extreme change in intake has been attributed to adjusting palatability and compensation for the lower energy diet (Biggs et al., 2004). While the current study hens were fed a 100\% wheat middling diet compared to the $94 \%$ used in previous studies. The remaining six percent was made up of dicalcium phosphate, salt, minerals and vitamins (Biggs et al., 2004). This could be potential difference the motivation of hens, either for palatability reasons or for the reason that eating more would not compensate for the already low energy deficiency. 
Observation of animal behavior can be used to assess an animal's state of wellbeing. Chicken behaviors that are reflective of reduced well-being have been characterized as an increase time spent pecking and scratching the floor, preening, spot pecking the feeder or side of the cage (Preston, 1987; Hocking et al., 1993). These behaviors are associated with hen frustration and increase when birds are restricted (Preston, 1987; Hocking et al., 1993). In a study comparing induced molt by feeding a diet containing 94\% wheat middling and 10 day feed withdrawal there was no difference between the two groups for the behaviors characterized (i.e., aggression, submission, pecked by neighbor, pecked a neighbor, feather pecking or escape stood on or stood upon; Biggs et al., 2004).

In conclusion, inducing hens to molt by incorporating MGA into a balanced layer diet addresses hen well-being concerns. In the current experiment there was no change in the motivation of hens to obtain feed because the total number of pecks and the total number or rewards did not change throughout the experiment. There was a difference in the total number of pecks and the total number of rewards in those groups receiving either the wheat middling diet or no feed. There was no change in the distance moved per half hour in the MGA group indicating with no change in feeding frustrations. 


\section{Literature Cited}

Biggs, P. E., M. E. Persia, K.W. Koelkebeck, C.M. Parsons. 2004. Further evaluation of nonfeed removal methods for molting programs. Poult. Sci. 83:745-752.

Biggs, P. E., M. W. Douglas, K. W. Koelkebeck, C. M. Parsons. 2003. Evaluation of nonfeed removal methods for molting programs. Poult. Sci. 82:749-753.

Bell, D. D. 2003. Historical and current molting practices in the U.S. table egg industry. Poult. Sci. 82:965-970.

Berry, W. D. 2003. The physiology of induced molting. Poult. Sci. 82:971-980.

Berry, W. D., J. Brake. 1987. Postmolt performance of laying hens molted by high dietary zinc, low dietary sodium, and fasting egg production and eggshell quality. Poult. Sci. 66:218-226.

Biggs, P. E., M. E. Persia, K.W. Koelkebeck, C.M. Parsons. 2004. Further evaluation of nonfeed removal methods for molting programs. Poult. Sci. 83:745-752.

DeJong, I. C., S. Van Voorst, D. A. Ehlhardt, H. J. Blokhuis. 2002. Effects of restricted feeding on physiology stress parameters in growing broiler breeders. Brit. Poult. Sci. 43:157-168.

Douglas, C. R., R. H. Harms, H. R. Wilson. 1972. The use of extremely low dietary calcium to alter the production pattern of laying hens. Poult. Sci. 51:2015-2020.

Gast, R. K., S. C. Ricket. 2003. Symposium: current and future prospects for induced molting in laying hens. Poult. Sic. 82:964.

Hocking, P. M., M. H. Maxwell, M. A. Mitchell. 1993. Welfare assessment of broiler breeder and layer females subjected to food restriction and limited access to water during rearing. Brit. Poult. Sci. 34:443-458. 
Huston, G. D. 1991. A note on hunger in the pig: sows on restricted rations will sustain an energy deficit to gain additional food. Anim. Prod. 52:233-235.

Lawrence, A. B., M. C. Appleby, A. W. Illius, H. A. MacLeod. 1989. Measuring hunger in the pig u sing operant conditioning: the effect of dietary bulk. Anim. Prod. 48:213-220.

Lawrence, A. B., A. W. Illius. 1989. Methodology for measuring hunger and food needs unsing operant coditioning in the pig. App. Anim. Beh. Sci. 24:273-285.

Lumijarvi, D. H., T. I. Koike, F. W. Hill. 1966. Effects of Na deficiency in the chick on water intake and fluid volumes, plasma electrolytes and plasma osmolality. Poult. Sci. 45:1100-1101.

National Research Council. 1994. Nutrient Recuirements of Poultry. $9^{\text {th }}$ rev. ed. National Academy Press. Washington, DC.

Nesbeth, W. G., C. R. Douglas, R. H. Harms. 1976. response of laying hens to low salt diet. Poult. Sci. 55:2128-2133.

Preston, A. P. 1987. Restricted feeding time and the behaviour of caged laying hens. Brit. Poult. Sci. 28:387-396.

Roberts, S., J. J. Matte, C. Farmer, C. L. Girard, G. P. Martineau. 1993. High-fiber diets for sows: effects on stereotypies and adjunctive drinking. App. Anim. Beh. Sci. 37:297-309. 
Roberts, S., J Rushen, C. Farmer. 1997. Both energy content and bulk of food affect stereotypic behaviour, heart rate and feeding motivation of female pigs. Appl. Anim. Beh. Sci. 54:161-171.

Savory, C. J., J. Lariviere. 2000. Effects of qualitative and quantitative food resection treatments on feeding motivational state and general activity level of growing broiler breeders. App. Anim. Behav. Sci. 69:135-147.

Savory, C. J., K. Maros, S. M. Rutter. 1993. Assessment of hunger in growing broiler breeders in relation to a commercial restricted feeding programme. Animal Welfare 2:131-152.

Seigle, H. S., 1961. Effect of level of dietary salt on the histology of the adrenal and kidney of young chickens. Poult. Sci. 40:1455-1456.

Shippee, R. L., P. E. Stake, U. Koehn, J. L. Lambert, R. W. Simmons. 1979. High dietary zinc or magnesium as forced-resting agents for laying hens. Poult. Sci. 58:949954. 


\section{General Discussion}

Melengestrol acetate (MGA) is an effective alternative to a feed withdrawal induced molt. Molting by MGA as an alternative method addresses the two major concerns associated with current alternative methods. First, it addresses industry concerns because it results in increased egg quality post-molt and is easily administered to a large population of hens. Second, it addresses a public concern for hen well-being because hens are maintained on a balanced layer diet and the MGA diet does not lead to weight loss or an increased motivation of the hens to obtain feed.

Feeding a balanced layer diet containing 4 or $8 \mathrm{mg}$ per day of MGA for 28 days results in reversible regression of the reproductive tract including the oviduct and its major components, the magnum and shell gland. Removing MGA from the diet at day 28, allows for rejuvenation of the oviduct to occur by day 44 . The regression of the reproductive tract is essential for the increase in post-molt performance, and the regression that was observed in those receiving 4 or $8 \mathrm{mg}$ per day of MGA was shown to result in increased post-molt performance.

Increased post-molt performance is determined by post-molt egg production and egg quality. Induced molting by incorporating 4 of $8 \mathrm{mg}$ per day of MGA in a balanced layer diet resulted in greater internal egg quality as measured by haugh units which is calculated using both albumen height and egg weight. External egg quality as measured by shell thickness was greater than controls in those groups receiving $4 \mathrm{mg}$ or $8 \mathrm{mg}$ of MGA per hen for all durations. External egg quality measured by breaking strength was greater than controls in both groups receiving 4 or $8 \mathrm{mg}$ per day of MGA at all durations. 
Feeding MGA as an alternative method to induce molting addresses the concerns that are raised with alternative methods to feed-withdrawal induced molt. MGA can be used to formulate a balanced layer diet that allows hens to be maintained on a balanced diet while undergoing the molting process. Feeding of a balanced layer diet containing MGA did not result in hen weight loss at any time throughout the experiment nor did it change a hen's motivation to obtain feed. Hens assigned to a wheat middling diet had a decreased motivation to obtain feed by the end of the experiment and those not fed had an increase in motivation to obtain feed by the ninth day of feed restriction. The total distanced moved was similar in those groups receiving a control diet or a balanced MGA diet. However, those hens that were not fed had increased the total distance that they moved by day 8 .

In conclusion, incorporation of MGA into a balanced layer diet is an effective method to induce molting. It results in an improved egg quality post-molt and addresses concerns about hen well-being during molting. 


\section{Literature Cited}

Adams, J. L. 1955. Progesterone-induced unseasonable molt in single comb white leghorn pullets. Poult. Sci. 34:702-707.

Adams, J. L. 1956. A comparison of different methods of progesterone administration to the fowl in affecting egg production and molt. Poult. Sci. 35:323-326.

Bahr, J. M., S.-C. Wang, M. Y. Huang, F. O. Calvo. 1983. Steroid concentration in isolated theca and granulosa layers of preovulatory follicles during the ovulatory cycle of the domestic hen. Bio. Repr. 29:326-334.

Barber, D. L., E. J. Sanders, R. Aebersold, W. J. Schneider. 1991. The receptor for yolk lipoprotein deposition in the chicken oocyte. Jour. Biol. Chem. 266:1876118770.

Barnett, J. L., P. H. Hemsworth. 1990. The validity of physiological and behavioural measures of animal welfare. App. Anim. Behav. Sci. 25:177-187.

Bell, D. D. 2003. Historical and current molting practices in the U.S. table egg industry. Poult. Sci. 82:965-970.

Bell, D. D., W. D. Weaver Jr. 2002. Comercial chicken and meat and egg production the $5^{\text {th }}$ edition.

Berry, W. D. 2003. The physiology of induced molting. Poult. Sci. 82:971-980.

Berry, W. D., J. Brake. 1987. Postmolt performance of laying hens molted by high dietary zinc, low dietary sodium, and fasting egg production and eggshell quality. Poult. Sci. 66:218-226.

Biggs, P. E., M. E. Persia, K.W. Koelkebeck, C.M. Parsons. 2004. Further evaluation of nonfeed removal methods for molting programs. Poult. Sci. 83:745-752. 
Biggs, P. E., M. W. Douglas, K. W. Koelkebeck, C. M. Parsons. 2003. Evaluation of nonfeed removal methods for molting programs. Poult. Sci. 82:749-753.

Brake, J., P. Thaxton. 1979. Physiological changes in chaged layers during forced molt. 2. Gross changes in organs. Poult. Sci. 58:707-716.

Cavlo, F. O., J. M. Bahr. 1983. Adenylyl cyclase system of the small preovulatoroy follicle of the domestic hen: responsiveness to follicle-stimulating hormone and luteinizing hormone. Biol. Repro. 29:543-547.

Chowdhury, V. S., Y. Yoshimura. 2004. Changes in the responsiveness of hen anterior pituitary to cLHRH-II during induced molting. Domestic Anim. Endo. 26:351359.

Deeley, R. G., K. P. Mulliniz, W. Wetekam, H. M. Kronenberg, M. Meyers, J. D. Eldridge, R. F. Goldberger. 1975. Vitellogenin synthesis in the avian liver. Jour. Biol. Chem. 250:9060-9066.

DeJong, I. C., S. V. Voorst, D. A., D. A. Ehlhardt, H. J. Blokhuis, 2002. Effects of restricted feeding on physiological stress parameters in growing broiler breeders. Brit. Poult. Sci. 43:157-168.

Dickerman, R. W., J. M. Bahr. 1989. Molt induced by gonadotropin-releasing hormone agonist as a model for studying endocrine mechanisms of molting in laying hens. Poult. Sci. 68:1402-1408.

Dilworth, B. C., E. J. Day. 1976. Sodium Depletion and repletion of white leghorn hens in cages. Poult Sci. 55:4593. (Abstr.)

Douglas, C. R., R. H. Harms, H. R. Wilson. 1972. The use of extremely low dietary calcium to alter the production pattern of laying hens. Poult. Sci. 51:2015-2020. 
Dube, M. G. A. Sahu, P. S. Kalra, S. P. Kalra. 1992. Neuropeptide Y reslease is elevated from the microdissected paraventricular nucleus of food-deprived rates: an in vitro study. Endo. 131:684-688.

Etches, R. J., C. E. Duke. 1984. Progesterone, androstenedione, and oestradiol content of theca and granulosa tissues of the four largest ovarian follicles during the ovulatory cycle of the hen (Gallus domesticus). Jour. Endo. 103:71-76.

Eroschenko, V. P., W. O. Wilson. 1974. Histological changes in the regressing reproductive organs of sexually mature male and female Japanese quail. Biol. Repro. 11:168-179.

Evans, M. I., P. J. O’Mally, A. Krust, J. B. E. Burch. 1987. Developmental regulation of the estrogen receptor and the estrogen responsiveness of five yolk protein genes in the avian liver. Proc. Natl. Acad. Sic. 88:8493-8497.

Ewing, S. A., D. C. Lay Jr., E. von Borell. 1999. Farm animal well-being, stress physiology, animal behavior and environmental design.

Gast, R. K., S. C. Ricket. 2003. Symposium: current and future prospects for induced molting in laying hens. Poult. Sic. 82:964.

Gilbert, R. W., R. Blair. 1975. A comparison of the effects of two low-calcium diets on egg production in the domestic fowl. Brit. Poult. Sci. 16:547-552.

Gordon, D. A., G. S. Shelness, M. Nicosia, D. L. Williams. 1988. Estrogen-induced destabilization of yolk precursor protein mRNAs in avian liver. Jour. Biol. Chem. 263:2625-2631.

Gorski, R. A. 1966. Localization and sexual differentiation of the nervous structures which regulate ovulation. J. Repr. Fert. Suppl. 1:67-88. 
Gabuten, A. R., C. S. Shaffner. 1954. A study of the physiological mechanisms affecting specific gravity of chicken eggs. Poult. Sci. 34:47-53.

Gutzwiller, J. P., L. Degen, L. Heuss, C. Beglinger. 2004. Glucagon-like peptide 1 (GLP1) and eating. Physio. and Beh. 82:17-19.

Hammond, R. W., W. H. Burke, F. Hertelendy. 1981. Influence of follicle maturation on progesterone release in the chicken granulosa cells in response to turkey and ovine gonadotrophins. Bio. Repr. 24:1048-1055.

Hocking, P. M., M. H. Maxwell, M. A. Mitchell. 1993. Welfare assessment of broiler breeders and layer females subjected to food restriction and limited access to water during rearing. Brit. Poult. Sci. 34:443-458.

Huang, E. S., K. J. Kao, A. V. Nalbandov. 1979. Synthesis of sex steroids by cellular components of the chicken follicles. Bio. Rep. 20:454-461.

Huston, G. D. 1991. A note on hunger in the pig:sows on restricted rations will sustain an energy deficit to gain additional food. Anim. Prod. 52:233-235.

Imai, K., A. V. Nalbandov. 1978. Plasma and follicular steroid levels of laying hens after the administration of gonadotropins. Bio. Rep. 19:779-784.

Johnson, A. L., J. T. Bridgham. 2001. Regulation of steroidogenic acute regulatory protein and luteinizing hormone receptor messenger ribonucleic acid in hen granulosa cells. Endo. 142:3116-3124.

Johnson, A. L., E. V. Solovieva, J. T. Bridgham. 2002. Relationship between steroidogenic acute regulatory protein expression and progesterone production in hen granulosa cells during follicle development. Bio. Repro. 67:1313-1320. 
Johnson, P. A., S. Stoklosowa, J. M. Bahr. 1987. Interaction of granuloasa and theca layers in the control of progesterone secretion in the domestic hen. Bio. Repr. 37:1149-1155.

Juhn, M., P. C. Harris. 1956. Responses in molt and lay of fowl to progestins and gonadotropins. Proc. Soc. Exp. Biol. Med. 92:709-711.

Koda, S., Y. Date, N. Murakami, T. Shimbara, T. Hanada, K. Toshinia, A. Niijima, M, Furuya, N. Inomata, K. Osuye, M. Nakazato. 2005. The role of the vagal nerve in peripheral PYY3-36-induced feeding reduction in rats. Endo. 2005.

Kohler, P. O., P. M. Grimley, B. W. O’Malley. 1969. Estrogen-induced cytodifferentation of the ovalbumin-secreting glands of the chick oviduct. Journ. Cell Biol. 40:8-27.

Kral, T. V. E., B. J. Roll. 2004. Energy density and portion size: their independent and combined effects on energy intake. Pysio. and Beh. 82:131-138.

Lawrence, A. B., M. C. Appleby, A. W. Illius, H. A. MacLeod. 1989. Measuring hunger in the pig using operant conditioning: the effect of dietary bulk. Anim. Prod. 48:213-220.

Lawrence, A. B., A. W. Illius. 1989. Methodology for measuring hunger and food needs unsing operant coditioning in the pig. App. Anim. Beh. Sci. 24:273-285.

Moran, T. H. 2004. Gut peptides in the control of food intake: 30 years of ideas. Physio. and Beh. 82:175-180.

Marrone, B. L., F. Hertelendy. 1983. Steroid metabolism by avian ovarian cells during follicular maturation. Bio. Repr. 29:953-962. 
National Research Council. 1994. Nutrient Recuirements of Poultry. $9^{\text {th }}$ rev. ed. National Academy Press. Washington, DC.

Nevalaine, T. J. 1969. The effect of calcium-deficient diet on the reproductive organs of the hen (Gallus domesticus). Poult. Sci. 48:653-659.

Nesbeth, W. G., C. R. Douglas, R. H. Harms. 1976a. The potential use of dietary salt deficiency for the force resting of laying hens. Poult. Sci. 55:2375-2379.

Nesbeth, W. G., C. R. Douglas, R. H. Harms. 1976b. Response of laying hens to low salt diet. Poult. Sci. 55:2128-2133.

Nitta, H., Y. Yoshio, J. M. Bahr. 1991. Multiple steroidogenic cell populations in the thecal layer of the preovulatory follicles of the chicken ovary. Endo. 129:20332040.

Oka, T. R. T. Schimke. 1969. Interactions of estrogen and progesterone in chicken oviduct development. Journ. Cell Biol. 40:816-831.

Opel, H. 1979. On hypothalamic control of ovulation in the turkey. Poult. Sci. 58:717724.

Prescott, N. B., C. M. Wathes. 2002. Preference and motivation of laying hens to eat under different illuminance and the effect of illuminance on eating behaviour. Brit. Poult. Sci. 43:190-195.

Preston, A. P. 1987. Restricted feeding time and the behaviour of caged laying hens. Brit. Poult. Sci. 28:387-396.

Pino, J. A., C. B. Hudson. 1953. Duration of sexual retardation in S.C. white leghorn pullets and cockerels following enheptin (2-amino, 5-nitrothiazole) feeding. Poult. Sci. 32:650-655. 
Ritzhaupt, L. K., J. M. Bahr. 1987. A decrease in FSH receptors of granulosa cells during follicular maturation in the domestic hen. Jour. Endoc. 115:303-310.

Roberts, S., J. J. Matte, C. Farmer, C. L. Girard, G. P. Martineau. 1993. High-fibre diets for sows: effects on stereotypies and adjunctive drinking. App. Anim. Beh. Sci. 37:297-309.

Roberts, S., J. Rushen, C. Farmer. 1997. Both energy content and bulk of food affect stereotypic behaviour, heart rate and feeding motivation of female pigs. Appl. Anim. Behav. Sci. 54:161-171.

Savory, C. J., J. Lariviere. 2000. Effects of qualitative and quantitative food resection treatments on feeding motivational state and general activity level of growing broiler breeders. App. Anim. Behav. Sci. 69:135-147.

Savory, C. J., K. Maros, S. M. Rutter. 1993. Assessment of hunger in growing broiler breeders in relation to a commercial restricted feeding programme. Animal Welfare 2:131-152.

Siegle, H. S., 1961. Effect of level of dietary salt on the histology of the adrenal and kidney of young chickens. Poult. Sci. 40:1455-1456.

Shaffner, C. S. 1954. Feather papilla stimulation by progesterone. Science. 120:345.

Shippee, R. L., P. E. Stake, U. Koehn, J. L. Lambert, R. W. Simmons. 1979. High dietary zinc or magnesium as forced-resting agents for laying hens. Poult. Sci. 58:949954.

Stanley, B. G., S. F. Leibowitz. 1985. Neuropeptide Y injected in the paraventricular hypothalamus: a powerful stimulant of feeding behavior. Proc. Natl. Acada. Sci. 82:3940-3943.0 
Van den Brand, H., S. J. Dieleman, N. M. Soede, B. Kemp. Dietary energy source at two feeding levels during lactation of primiparous sows: I. Effects on glucose, insulin, and luteinizing hormone and on follicle development, weaning-to-estrus interval, and ovulation rate. Journ. Anim. Sci. 78:396-404.

Yoshimura, I., J. M. Bahr. 1991. Localization of progesterone receptors in the shell gland of laying and nonlaying chickens. Poult Sci. 70:1246-1251.

Yoshimura, Y., B. Heryanto, T. Tamura. 1997. Changes in the population of proliferatin cells in chickens anterior pituitary during induced molting: an immunocytochemical analysis for proliferating cell nuclear antigen. Poult. Sci. $76: 1569-1573$

Yu, J. Y.-L., R. R. Marquardt. 1973. Development, cellular growth, and function of the avian oviduct. Studies on the magnum during a reproductive cycle of the domestic fowl (Gallus Domesticus). Biol. Repro. 8:283-298. 